\title{
Classical dendritic cells regulate acute lung inflammation and injury in mice with lipopolysaccharide-induced acute respiratory distress syndrome
}

\author{
${\text { LANG } \mathrm{LI}^{1,2}, \text { LIANG DONG }}^{1,2}$, DAN ZHAO $^{2}$, FEI GAO $^{2}$ and JIE YAN ${ }^{2}$ \\ ${ }^{1}$ Department of Critical Care Medicine, Taizhou Central Hospital, Taizhou University Hospital, Taizhou, \\ Zhejiang 318000; ${ }^{2}$ Department of Critical Care Medicine, Wuxi People's Hospital, \\ Nanjing Medical University, Wuxi, Jiangsu 214023, P.R. China
}

Received December 26, 2018; Accepted May 22, 2019

DOI: $10.3892 / \mathrm{ijmm} .2019 .4208$

\begin{abstract}
Classical dendritic cells (cDCs) are involved in the pathogenesis of inflammatory lung diseases; however, their contributions in acute respiratory distress syndrome (ARDS), which is pathophysiologically inflammatory, remain unknown. The present study aimed to explore the regulatory effects of pulmonary cDCs on acute lung inflammation and injury in lipopolysaccharide (LPS)-induced ARDS. Fms-like tyrosine kinase 3-ligand (FLT3L) and lestaurtinib, a specific activator and an inhibitor of FLT3 signaling respectively, were used separately for the pretreatment of C57BL/6 mice for 5 consecutive days. ARDS was induced by intratracheal injection of LPS, and mice were sacrificed 6 and $24 \mathrm{~h}$ later. Flow cytometry was used to measure the aggregation and maturation of pulmonary cDCs. The ratio of lung wet weight to body weight (LWW/BW) and histopathological analyses were assessed to evaluate lung edema and lung injury. Tumor necrosis factor- $\alpha$ and interleukin (IL)-6 levels were measured by ELISA to evaluate acute lung inflammation. The levels of interferon- $\gamma$, IL-1 $\beta$, IL- 4 and IL-10, and the expression of the transcription factors T-box-expressed-in-T-cells (T-bet) and GATA binding protein 3 , were quantified by ELISA, RT-qPCR and western blotting to evaluate the balance of the Th1/Th2 response. Myeloperoxidase (MPO) activity was measured to evaluate neutrophil infiltration. The results demonstrated that the aggregation and maturation of pulmonary cDCs reached a peak at $6 \mathrm{~h}$ after LPS challenge, followed by a significant decrease at $24 \mathrm{~h}$. FLT3L pretreatment further stimulated the aggregation and maturation of pulmonary $\mathrm{cDCs}$, resulting
\end{abstract}

Correspondence to: Dr Liang Dong, Department of Critical Care Medicine, Taizhou Central Hospital, Taizhou University Hospital, 999 Donghai Avenue, Taizhou, Zhejiang 318000, P.R. China E-mail: dongliang@njmu.edu.cn

Key words: acute respiratory distress syndrome, dendritic cells, inflammation, neutrophil infiltration, $\mathrm{T}$ helper cell response, pathogenesis in elevated lung MPO activity and increased T-bet expression, which in turn led to aggravated LWW/BW, acute lung inflammation and injury. However, lestaurtinib pretreatment inhibited the aggregation and maturation of pulmonary cDCs, decreased lung MPO activity and T-bet expression, and eventually improved LWW/BW, acute lung inflammation and injury. The present results suggested that pulmonary cDCs regulated acute lung inflammation and injury in LPS-induced ARDS through the modulation of neutrophil infiltration and balance of the Th1/Th2 response.

\section{Introduction}

Acute respiratory distress syndrome (ARDS) represents the most severe form of acute noncardiogenic refractory respiratory failure and is associated with high morbidity and mortality in critically ill patients $(1,2)$. Numerous studies have emphasized the importance of uncontrolled inflammation in the pathogenesis of ARDS; however, the fundamental cellular mechanisms that regulate acute lung inflammation and injury in ARDS still require to be clarified $(3,4)$.

Classical dendritic cells (cDCs), which exist in the lung in relatively small numbers, are ideally positioned to serve a priming and central role in the immune response during infection/inflammation $(5,6)$. cDCs are pivotal antigen-presenting cells (APCs); the involvement of pulmonary cDCs in the pathogenesis of ARDS has been revealed in several recent studies, wherein cDCs were found to act as pro-inflammatory initiators and mediators $(7,8)$. However, the precise mechanism by which pulmonary cDCs affect acute lung inflammation remains to be clarified.

Fms-like tyrosine kinase 3 (FLT3), to which FLT3-ligand (FLT3L) binds, represents an important hematopoietic factor that is abundantly expressed on hematopoietic stem cells and DC progenitors $(9,10)$. FLT3 signaling is one of the most important pathways that manage the entire lifespan of DCs. Once FLT3L binds to FLT3, the FLT3 signaling is activated, leading to the aggregation of functional DCs, stimulation of DC maturation and decreased apoptosis of mature DCs $(9,11)$. By contrast, inhibition of FLT3 signaling with lestaurtinib is associated with decreased aggregation and maturation of 
cDCs $(9,12)$. Our previous pilot study also indicated that FLT3 signaling controls the accumulation and maturation of cDCs in mouse models of acute lung injury (13). Therefore, FLT3 signaling may represent a reliable approach for the manipulation of cDCs in vivo.

Although the mechanisms responsible for the pathogenesis of ARDS remain controversial, previous studies have suggested that cDCs may contribute to the pathology of ARDS by regulating several processes, such as polarizing the $\mathrm{T}$ helper cell $(\mathrm{Th}) 1$ response and regulating neutrophil infiltration $(1,9)$. Generally, Th cells are the primary target of cDC manipulation, leading to a shifted balance between Th1 and Th2 responses (14). Previous studies have reported that aggregation and maturation of cDCs results in a Th1-skewed cytokine pattern, thus aggravating the inflammatory response, whereas inhibited expansion and maturation of cDCs was associated with a Th2-skewed cytokine pattern $(9,15)$. Recently, cDCs have also been implicated in crosstalk with neutrophils, such as reinforcing the recruitment of neutrophils, prolonging neutrophil survival and inducing the upregulation of the innate immune response $(16,17)$. In summary, favoring the Th1 response and enhancing neutrophil infiltration may be two underlying mechanisms by which cDCs participate in the development of acute lung inflammation during lipopolysaccharide (LPS)-induced ARDS.

The purpose of the present study was to explore whether pulmonary cDCs manage lung inflammation and injury during LPS-induced ARDS and the mechanisms by which pulmonary cDCs affect lung inflammation and injury in vivo.

\section{Materials and methods}

Animals. Seventy-five specific-pathogen-free male C57BL/6 mice (age, 6-8 weeks; weight, 20-25 g) were purchased from the Laboratory Animal Center, Academy of Military Medical Sciences of People's Liberation Army (Beijing, China). Mice were maintained under specific pathogen-free conditions with a 12 -h light/dark cycle (temperature, $18-23^{\circ} \mathrm{C}$; humidity, 40-60\%) and fed standard rodent food and water ad libitum. All animal experiments were conducted in accordance with the National Institutes of Health Guide for the Care and Use of Laboratory Animals and with the approval of the Institutional Animal Care and Use Committee of Nanjing Medical University.

Murine ARDS model. The murine ARDS model was induced as previously described with minor modifications (18). Briefly, mice were anesthetized by an intraperitoneal injection of $50 \mathrm{mg} / \mathrm{kg}$ pentobarbital, and a midline incision was made in the neck to expose the trachea. ARDS was generated by a direct intratracheal instillation of LPS $(2 \mathrm{mg} / \mathrm{kg}$; Escherichia coli 0111:B4; Sigma-Aldrich; Merck KGaA) through a tracheostomy, and the incision was sutured. Mice were returned to the cage until fully awake.

Experimental groups and sample acquisition. Mice were randomly allocated to one of the following groups $(n=15$ mice per group): Control group, mice received intratracheal administration of $0.9 \%$ normal saline (NS); ARDS group, mice received $2 \mathrm{mg} / \mathrm{kg}$ LPS to establish the ARDS model;
FLT3L+ARDS group, mice received $10 \mu \mathrm{g} / \mathrm{d}$ FLT3L for 5 days followed by $2 \mathrm{mg} / \mathrm{kg}$ LPS; lestaurtinib+ARDS group, mice received $40 \mathrm{mg} / \mathrm{kg} / \mathrm{d}$ lestaurtinib for 5 days followed by $2 \mathrm{mg} / \mathrm{kg}$ LPS; and DMSO+ARDS group, mice were pretreated with an equal volume of 10\% DMSO for 5 days (DMSO was the solvent for lestaurtinib, and therefore used here as a vehicle control) followed by $2 \mathrm{mg} / \mathrm{kg}$ LPS. FLT3L (LC Laboratories), lestaurtinib (Miltenyi Biotec, $\mathrm{GmbH}$ ) and DMSO (Sigma-Aldrich; Meck KGaA) were all administered subcutaneously. Mice were euthanized by barbital overdose at 6 or $24 \mathrm{~h}$ following LPS challenge. These two post-insult time-points were selected because they are critical points for the aggregation and maturation of cDCs $(19,20)$, and they could pathophysiologically represent the early-phase and late-phase of ARDS, respectively $(21,22)$. The whole lung was removed and perfused with saline/EDTA to wipe out the intravascular blood cells. Specimens were snap-frozen in liquid nitrogen and stored at $-80^{\circ} \mathrm{C}$ for subsequent measurements.

Measurement of the aggregation and maturation of pulmonary cDCs by flow cytometry. The aggregation of pulmonary cDCs was quantified using the relative percentage of cDCs among total lung cells $(23,24)$. The maturation of pulmonary cDCs was quantified using the percentage of expression of major histocompatibility complex class II (MHC II) and CD80 in all pulmonary cDCs (5). Briefly, the entire left lung was collagenase-digested into single-cell suspension, as previously described (25). After red blood cell lysis and $\mathrm{Fc}$ receptor blockade, cells were stained with monoclonal antibodies or their corresponding isotype controls, according to the manufacturer's recommendations: Cells were incubated with FITC-labeled anti-CD11c, Percp-cy5.5-labeled anti-CD11b, PE-labeled anti-MHC II and APC-labeled anti-CD80 (all at 1:100 dilution; cat. nos. 11-0114-82, 45-0112-82, 12-5321-82, 17-0801-82; eBioscience; Thermo Fisher Scientific, Inc.) at $4^{\circ} \mathrm{C}$ for $30 \mathrm{~min}$, then washed and resuspended with PBS. The cells were fixed in $1 \%$ paraformaldehyde at $25^{\circ} \mathrm{C}$ for $1 \mathrm{~h}$ and kept in the dark at $4^{\circ} \mathrm{C}$ until analysis. CD11c/CD11b double-positive cells represent pulmonary cDCs $(23,26)$. CD11c/CD11b/MHC II or $\mathrm{CD} 11 \mathrm{c} / \mathrm{CD} 11 \mathrm{~b} / \mathrm{CD} 80$ triple-positive cells represent mature cDCs $(26,27)$. Flow cytometry analysis was conducted using a FACSCanto (BD Biosciences) and CellQuest software (BD Biosciences). For each analysis, 20,000 events were recorded.

Pulmonary myeloperoxidase (MPO) activity assay. MPO activity, an index of neutrophil infiltration in the lung, was measured by chromometry, as previously described, using a commercially available kit (Nanjing Jiancheng Bioengineering Institute) (28). In brief, MPO was extracted from homogenized lung tissue (10 mg per assay) by suspending the sample in $0.5 \%$ hexadecyl trimethyl ammonium bromide in $0.5 \mathrm{ml}$ of potassium phosphate buffer $(10 \mathrm{mmol} / 1, \mathrm{pH} 7.0)$. A $0.2 \mathrm{ml}$ aliquot of homogenate was mixed with a $1.6 \mathrm{mmol} / \mathrm{l}$ solution of tetramethyl benzidine and $0.1 \mathrm{mmol} / 1 \mathrm{H}_{2} \mathrm{O}_{2}$. The rate of change in absorbance at $460 \mathrm{~nm}$ was measured by an MK3 spectrophotometer (Thermo Fisher Scientific, Inc.). MPO activity was expressed as units per gram of the sample. 
Tumor necrosis factor (TNF)- $\alpha$, interleukin (IL)-6, interferon (IFN)- $\gamma, I L-1 \beta, I L-4$ and IL-10 assay. The right lower lobe was weighted and homogenized. The homogenate was then centrifuged at $1,000 \mathrm{x}$ g for $5 \mathrm{~min}$ at $4^{\circ} \mathrm{C}$ and the supernatant was harvested. The concentrations of TNF- $\alpha$, IL-6 IFN- $\gamma$, IL-1 $\beta$, IL-4 and IL-10 in the supernatant were measured using commercial ELISA kits (cat. nos. EM008-96, EM004-96, EM007-96, EM001-96, EM003-96 and EM005-96; ExCell Biology, Inc.), according to the manufacturer's protocols. The concentrations were expressed as picograms per milligram of the sample.

Determination of mRNA expression levels of Akt, ERK1/2, STAT5, T-box-expressed-in-T-cells (T-bet) and GATA binding protein 3 (GATA-3). mRNA expression in lung tissues was measured by reverse transcription-quantitative PCR (RT-qPCR). Briefly, lung tissues (10 mg per assay) were harvested and homogenized, and the total RNA was extracted using TRIzol reagent (Takara Biotechnology Co., Ltd.). A total of $5 \mu \mathrm{g}$ of total RNA was subsequently reverse transcribed to cDNA, using the High-Capacity cDNA Reverse Transcription kit (Thermo Fisher Scientific, Inc.), according to the manufacturer's protocol. An ABI PRISM 7300 Sequence Detection System (Applied Biosystems; Thermo Fisher Scientific, Inc.) was used for PCR amplification. Each sample was analyzed in triplicate with the following thermocycling conditions: 40 cycles, including a denaturation step at $95^{\circ} \mathrm{C}$ for $15 \mathrm{sec}$, an annealing step at $56^{\circ} \mathrm{C}$ for $20 \mathrm{sec}$ and an extension step at $72^{\circ} \mathrm{C}$ for $40 \mathrm{sec}$. SYBR Green I (Thermo Fisher Scientific, Inc.) was selected as the fluorophore dye. The $2^{-\Delta \Delta C q}$ method was used to calculate the relative expression of mRNA, and $\beta$-actin was used as the internal reference gene (29). The primers used were as follows: Akt, forward 5'-TCTATGGCGCTGAGA TTGTG-3' and reverse 5'-CTTAATGTGCCCGTCCTTGT-3'; ERK1, forward 5'-TCCGCCATGAGAATGTTATAGGC-3' and reverse 5'-GGTGGTGTTGATAAGCAGATTGG-3'; ERK2, forward 5'-GGTTGTTCCCAAATGCTGACT-3' and reverse 5'-CAACTTCAATCCTCTTGTGAGGG-3'; STAT5, forward 5'-AGTATTACACTCCTGTACTTGCGAAAG-3' and reverse 5'-GGAGCTTCTAGCGGAGGTGAAGAG ACC-3'; T-bet, forward 5'-ACCACCTGTTGTGGTCCAAG-3' and reverse 5'-CACCAAGACCACATCCACAA-3'; GATA-3, forward 5'-ACCGGGTTCGGATGTAAGTC-3' and reverse 5'-AGGCATTGCAAAGGTAGTGC-3'; and $\beta$-actin, forward 5'-CCTCTATGCCAACACAGTGC-3' and reverse 5'-GTA CTCCTGCTTGCTGATCC-3'.

Determination of protein expression levels of Akt, ERK1/2, STAT5, T-bet, GATA-3 and FLT3L. Protein expression in lung tissue was measured by western blotting. Briefly, the ReadyPrep ${ }^{\mathrm{TM}}$ Protein Extraction kit (cat. no. 1632086; Bio-Rad Laboratories, Inc.) was used to extract the total protein. A BCA assay was used to measure the protein concentration. Proteins were denatured and added to the wells in aliquots of $25 \mu \mathrm{g}$ per well. After SDS-PAGE (10\%), the proteins were transferred to a polyvinylidene fluoride membrane, blocked with Tris-buffered saline with Tween-20 (TBST) containing $5 \%$ skim milk powder at $25^{\circ} \mathrm{C}$ for $1 \mathrm{~h}$, and incubated at $4^{\circ} \mathrm{C}$ overnight with primary antibodies against phosphorylated (p-) Akt, total Akt,p-ERK1/2,total ERK1/2,p-STAT5, total STAT5 (all at 1:400 dilution; cat. nos. ab38449, ab8805, ab201015, ab17942, ab32364, ab16276; Abcam), T-bet, GATA-3, FLT3L and $\beta$-actin (all at 1:400 dilution; cat. nos. sc-21763, sc-130057, sc-365266, sc-47778; Santa Cruz Biotechnology, Inc.). $\beta$-actin was used as an internal reference protein. The membrane was washed three times with TBST and incubated with horseradish peroxidase-conjugated secondary antibody (1:1,000 dilution; cat. no. A0216; Beyotime Institute of Biotechnology) at $25^{\circ} \mathrm{C}$ for $1 \mathrm{~h}$. The membrane was washed four times with TBST, developed with the Pierce ${ }^{\mathrm{TM}}$ Enhanced Chemiluminescence reagent (Thermo Fisher Scientific, Inc.) and placed on an X-ray film for imaging. Quantity One 4.6.7 software (Bio-Rad Laboratories, Inc.) was used for quantitative analysis of the grayscale values of the bands.

Evaluation of lung edema. Lung edema was assessed by the ratio of lung wet weight to body weight (LWW/BW) (30). In brief, the intact lung was harvested and trimmed to remove extra-pulmonary tissues, and the LWW/BW was calculated based on the recorded lung wet weight and body weight.

Lung histopathological analysis. The right upper lobe was fixed in $10 \%$ neutral formaldehyde at $4^{\circ} \mathrm{C}$ for $24 \mathrm{~h}$ and embedded in paraffin. After consecutively transverse slicing into $5-\mu \mathrm{m}$-thick sections and sequentially staining with hematoxylin for $5 \mathrm{~min}$ and eosin for $2 \mathrm{~min}$ at $25^{\circ} \mathrm{C}$, 10 high-magnification ( $\mathrm{x} 400$; light microscopy) visual fields were randomly selected for semi-quantitative evaluation of lung injury based on the method reported by Smith et al (31), and the mean sum of each field score was determined.

Statistical analysis. Statistical analyses were conducted using the SPSS 16.0 software package (SPSS, Inc.) All data were presented as the means \pm standard deviation. For multiple group comparison, a one-way analysis of variance followed by Bonferroni's post hoc test was used. For two-group comparison, the Mann-Whitney U test was applied. $\mathrm{P}<0.05$ was considered to indicate a statistically significant difference.

\section{Results}

Regulation of FLT3 signaling in lung tissue by FLT3L and lestaurtinib. The mRNA and protein expression levels of Akt, ERK1/2 and STAT5 were measured to confirm the regulation of FLT3 signaling by FLT3L and lestaurtinib. The results demonstrated that the mRNA expression levels of Akt, ERK1/2 and STAT5 exhibited no significant difference among the groups (Fig. 1A-C). However, FLT3L pretreatment in the FLT3L+ARDS group significantly increased the phosphorylation of Akt, ERK1/2 and STAT5 compared with the ARDS group alone $(\mathrm{P}<0.05$; Fig. $1 \mathrm{D}-\mathrm{G})$, and lestaurtinib pretreatment in the lestaurtinib + ARDS group significantly decreased the phosphorylation of Akt, ERK1/2 and STAT5 compared with the DMSO+ARDS vehicle control group (P<0.05; Fig. 1D-G). These results indicated that FLT3L and lestaurtinib could effectively activate and suppress FLT3 signaling, respectively.

Aggregation and maturation of cDCs peaks as early as $6 \mathrm{~h}$ following LPS challenge. To observe the maximum effect of FLT3 signaling on the aggregation and maturation of cDCs 

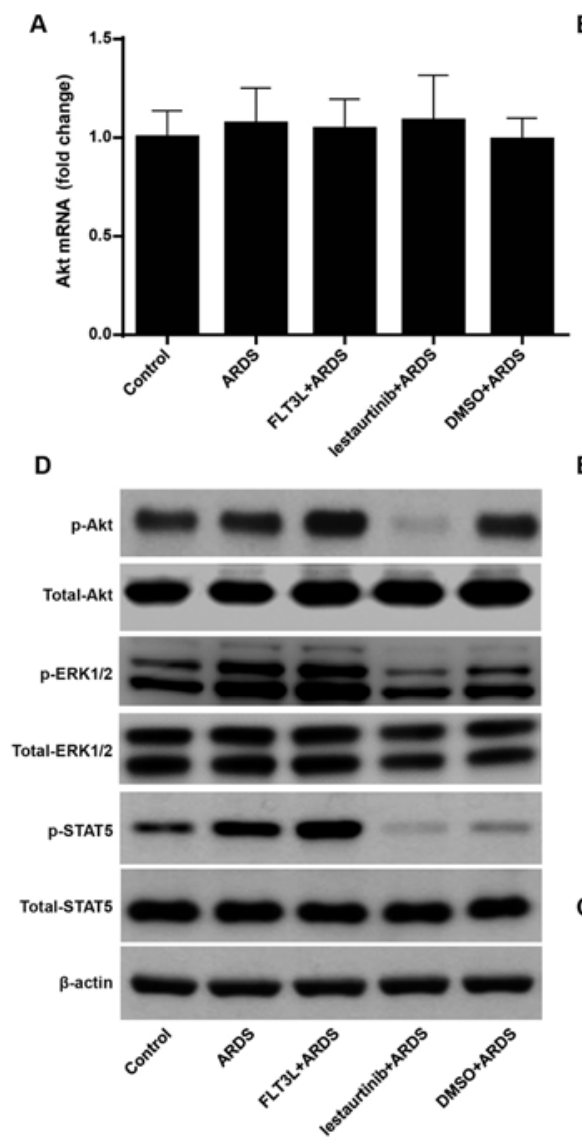

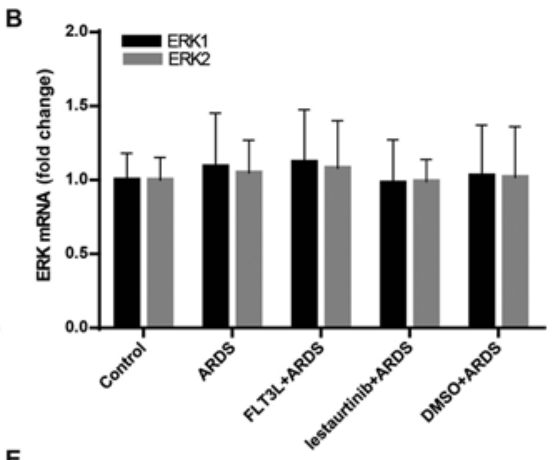

E
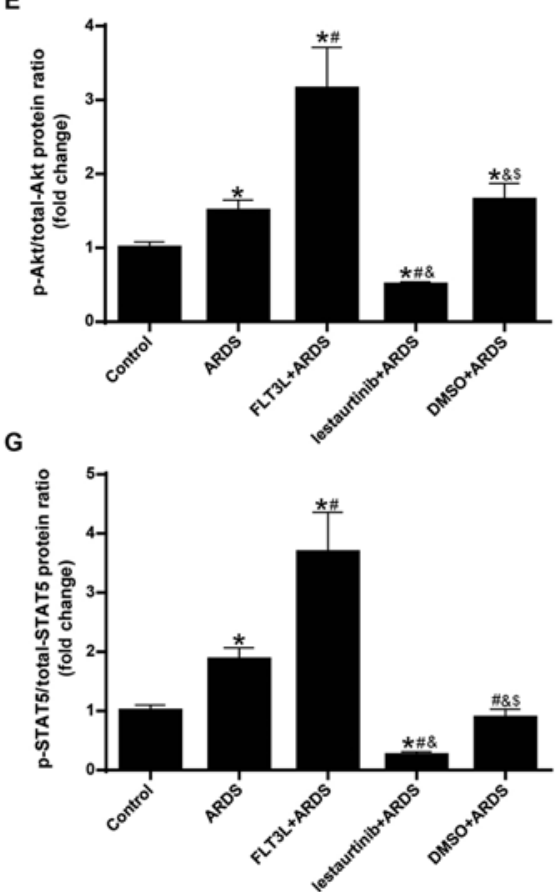
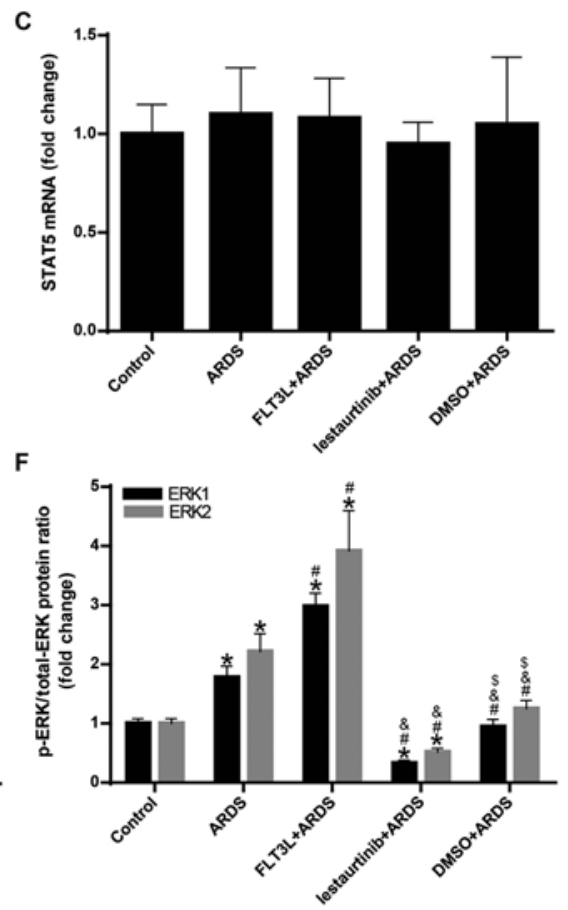

Figure 1. Regulation of FLT3 signaling in lung tissue by FLT3L and lestaurtinib. mRNA and protein expression levels of Akt, ERK1/2 and STAT5 were measured by reverse transcription-quantitative PCR and western blotting, respectively, to confirm regulation of FLT3 signaling by FLT3L and lestaurtinib. (A) mRNA expression of Akt. (B) mRNA expression of ERK1/2. (C) mRNA expression of STAT5. $\beta$-actin was used as a reference gene. (D) Western blot analysis of Akt,ERK1/2 and STAT5 and their phosphorylated forms. (E) Ratio of p-Akt to total Akt levels. (F) Ratio of p-ERK to total ERK levels. (G) Ratio of p-STAT5 to total STAT5 levels. $\beta$-actin was used as a reference protein. Data are presented as the mean \pm standard deviation $(\mathrm{n}=3)$. ${ }^{*} \mathrm{P}<0.05$ vs. Control; ${ }^{*} \mathrm{P}<0.05$ vs. ARDS; ${ }^{\circledR} \mathrm{P}<0.05$ vs. FLT3L+ARDS; and ${ }^{\$} \mathrm{P}<0.05$ vs. lestaurtinib+ARDS. FLT3, Fms-like tyrosine kinase 3; FLT3L, Fms-like tyrosine kinase 3-ligand; p-, phosphorylated; ARDS, acute respiratory distress syndrome.

at early-phase of ARDS $(19,21)$, the aggregation and maturation of cDCs was measured at $6 \mathrm{~h}$ following LPS challenge. Compared with the control group, both the percentage of pulmonary cDCs (Fig. 2A and B) and the percentage of MHC II-expressing cDCs (Fig. 2C and D) were significantly increased in the ARDS group just $6 \mathrm{~h}$ after LPS challenge $(\mathrm{P}<0.05)$.

To observe the effect of FLT3 signaling on the aggregation and maturation of cDCs at late-phase of ARDS $(20,22)$, the aggregation and maturation of cDCs was measure at $24 \mathrm{~h}$ following LPS challenge. Compared with the control group, both the percentage of pulmonary cDCs (Fig. 2A and B) and the percentage of MHC II-expressing cDCs (Fig. 2C and D) remained higher in the ARDS group at $24 \mathrm{~h}$ after LPS challenge $(\mathrm{P}<0.05)$. However, the effect was gradually reduced at $24 \mathrm{~h}$ compared to $6 \mathrm{~h}$ for the ARDS group (Fig. 2B and D; $\mathrm{P}<0.05)$. Notably, the expression levels of CD80 on pulmonary cDCs remained unchanged at $6 \mathrm{~h}$ after LPS challenge between the control group and the ARDS group (Fig. 2E and F); however, a subsequent sharp increase was observed at $24 \mathrm{~h}$ after LPS challenge (Fig. 2E and F; $\mathrm{P}<0.05$ ).

Aggregation and maturation of cDCs is modulated by FLT3 signaling. The aggregation and maturation of pulmonary cDCs was assessed at $6 \mathrm{~h}$ following LPS challenge to confirm the DC-targeting property of FLT3 signaling in vivo. As expected, FLT3L pretreatment in the FLT3L+ARDS group was associated with a significant increase in the percentage of pulmonary cDCs just $6 \mathrm{~h}$ after LPS challenge compared with the ARDS alone group (Fig. 3A and B). Furthermore, lestaurtinib pretreatment in the lestaurtinib+ARDS group significantly reduced the percentage of pulmonary cDCs at $6 \mathrm{~h}$ after LPS challenge compared with the vehicle control DMSO+ARDS group (Fig. 3A and B).

The expression of MHC II and CD80 was further examined in the pulmonary cDCs, in order to evaluate their maturation. FLT3L pretreatment in the FLT3L+ARDS group significantly increased the expression of MHC II in pulmonary 
A
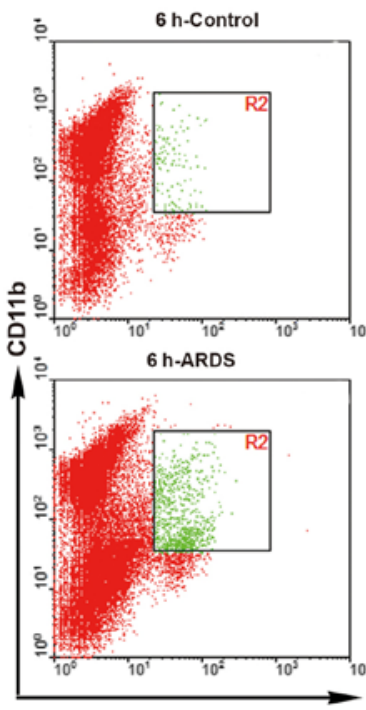

C
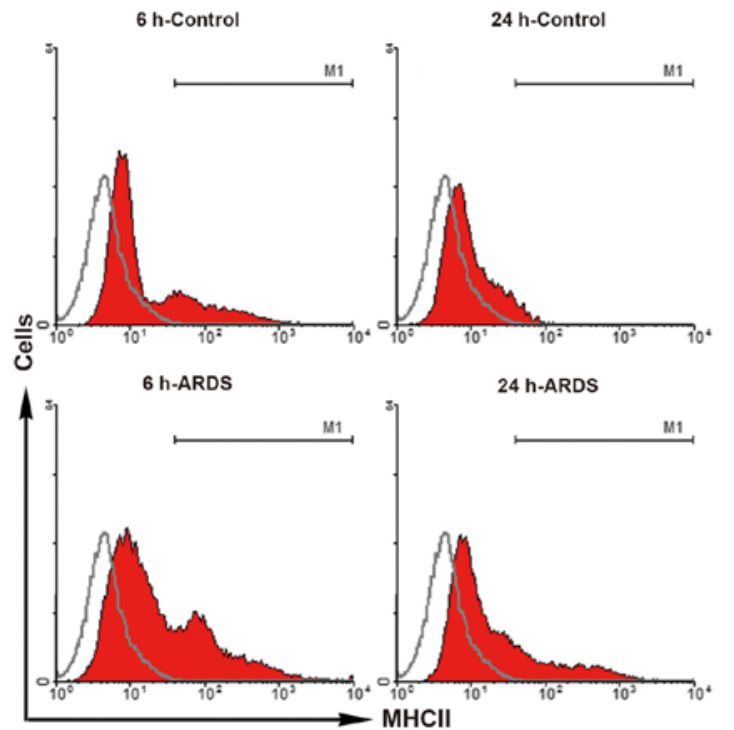

M1

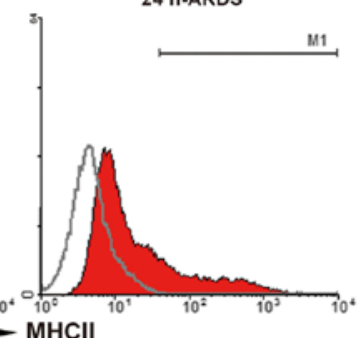

$E$

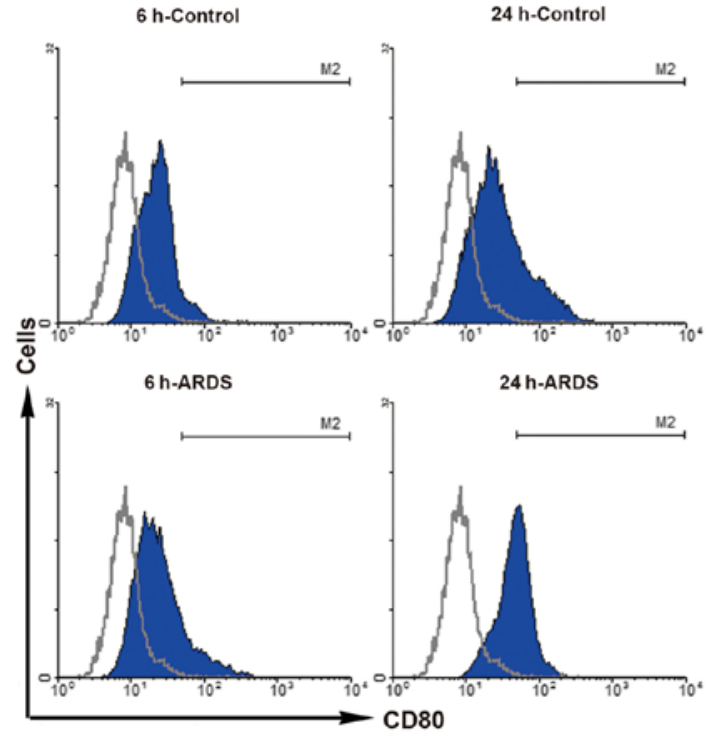

B

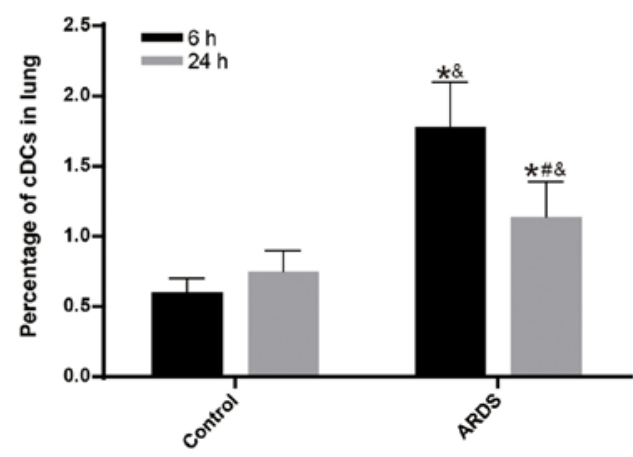

D

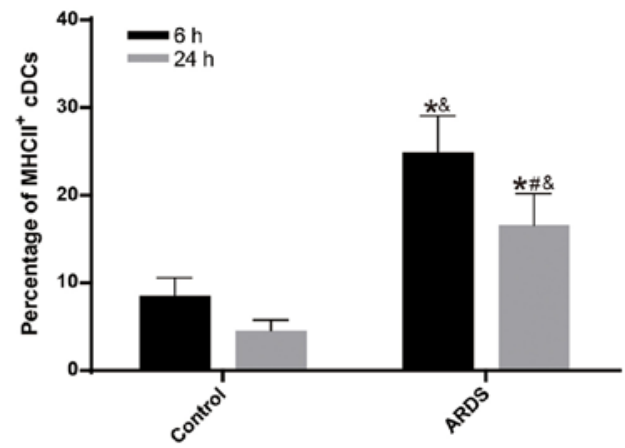

$\mathbf{F}$

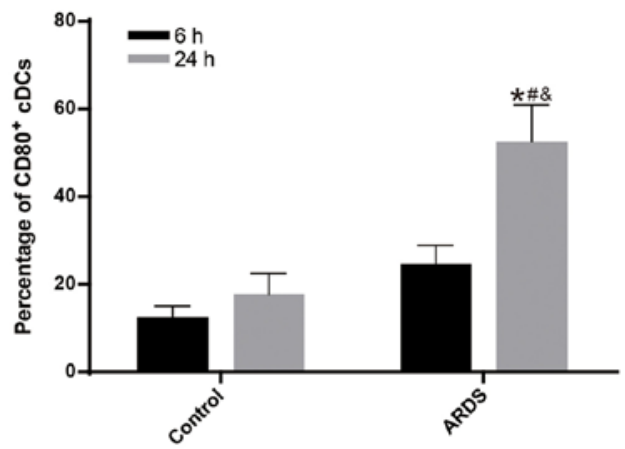

Figure 2. Aggregation and maturation of pulmonary cDCs peaks at $6 \mathrm{~h}$ post-LPS challenge. The aggregation and maturation of pulmonary cDCs were measured by flow cytometry. (A) Representative dot plots and (B) quantification showing the percentage of cDCs (CD11c $\left.\mathrm{c}^{+} \mathrm{CD} 11 \mathrm{~b}^{+}\right)$among total lung cells in the control and ARDS groups at 6 and $24 \mathrm{~h}$ post-LPS challenge. (C) Representative histograms and (D) quantification showing the expression of MHC II in pulmonary cDCs in the control and ARDS groups at 6 and $24 \mathrm{~h}$ post-LPS challenge. (E) Representative histograms and (F) quantification showing the expression of CD80 in pulmonary cDCs in the control and ARDS groups at 6 and $24 \mathrm{~h}$ post-LPS challenge. Results are presented as the mean \pm standard deviation of values obtained from six mice per group at each time point. Gray histograms represent the isotype control. ${ }^{~} \mathrm{P}<0.05 \mathrm{vs} .6 \mathrm{~h}-\mathrm{Control} ;{ }^{*} \mathrm{P}<0.05$ vs. $6 \mathrm{~h}$-ARDS; and \& $\mathrm{P}<0.05$ vs. $24 \mathrm{~h}$-Control. cDCs, classical dendritic cells; LPS, lipopolysaccharide; ARDS, acute respiratory distress syndrome; MHC II, major histocompatibility complex class II. 
A
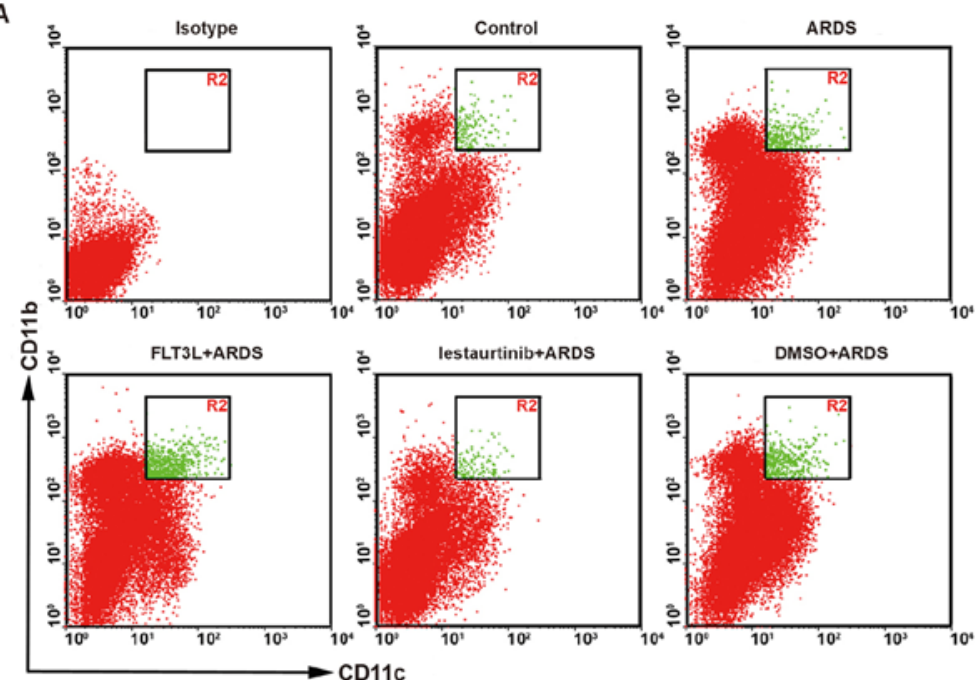

B

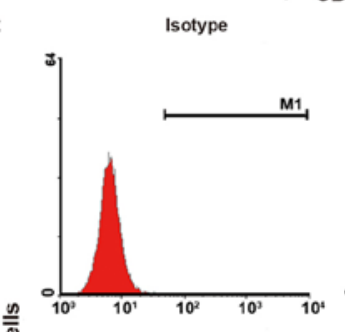

Control

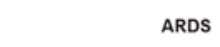

$$
\frac{n}{\bar{\delta}}
$$
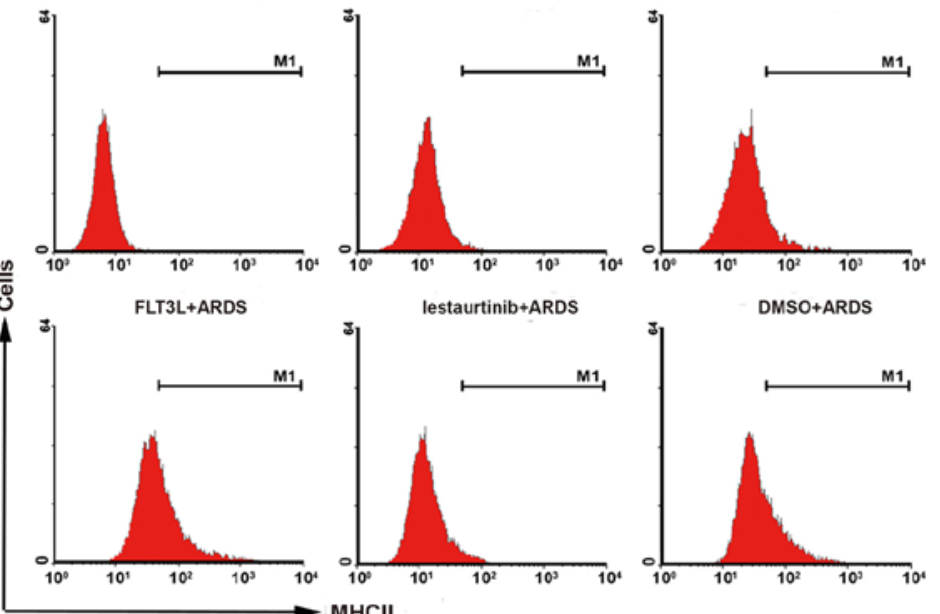

D

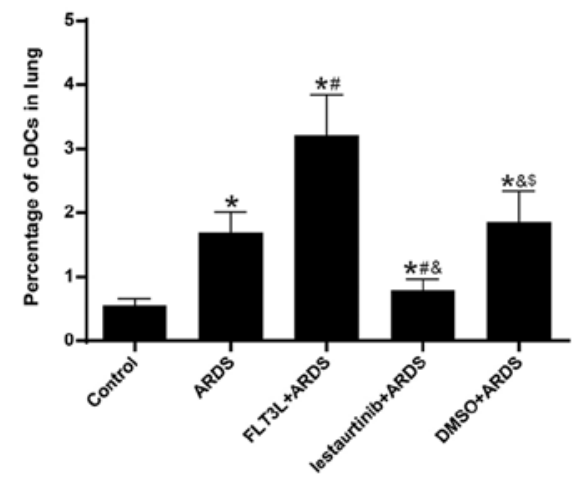

DMSO+ARDS
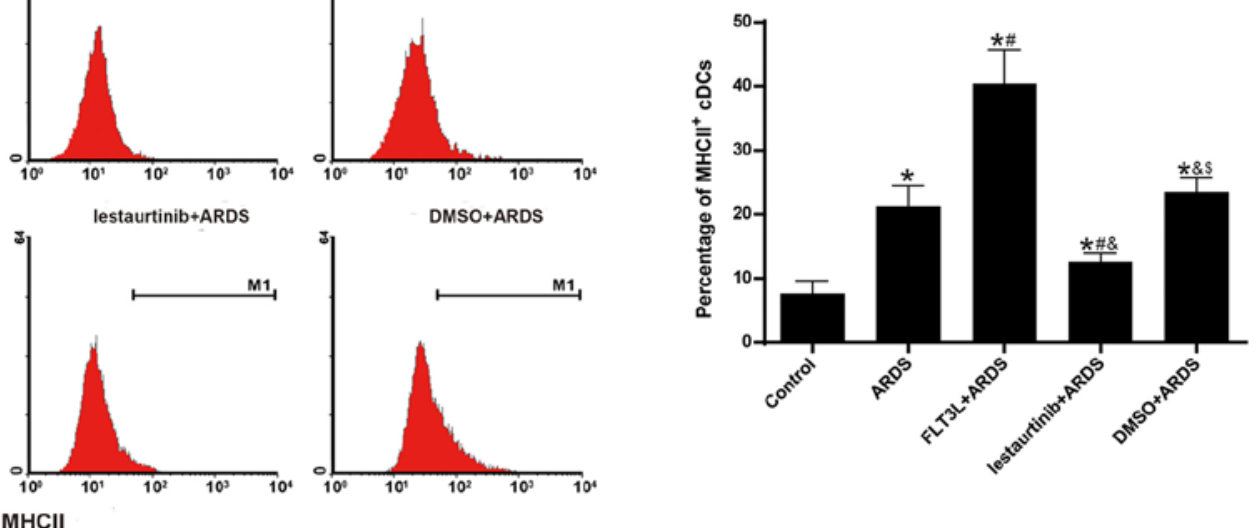

E
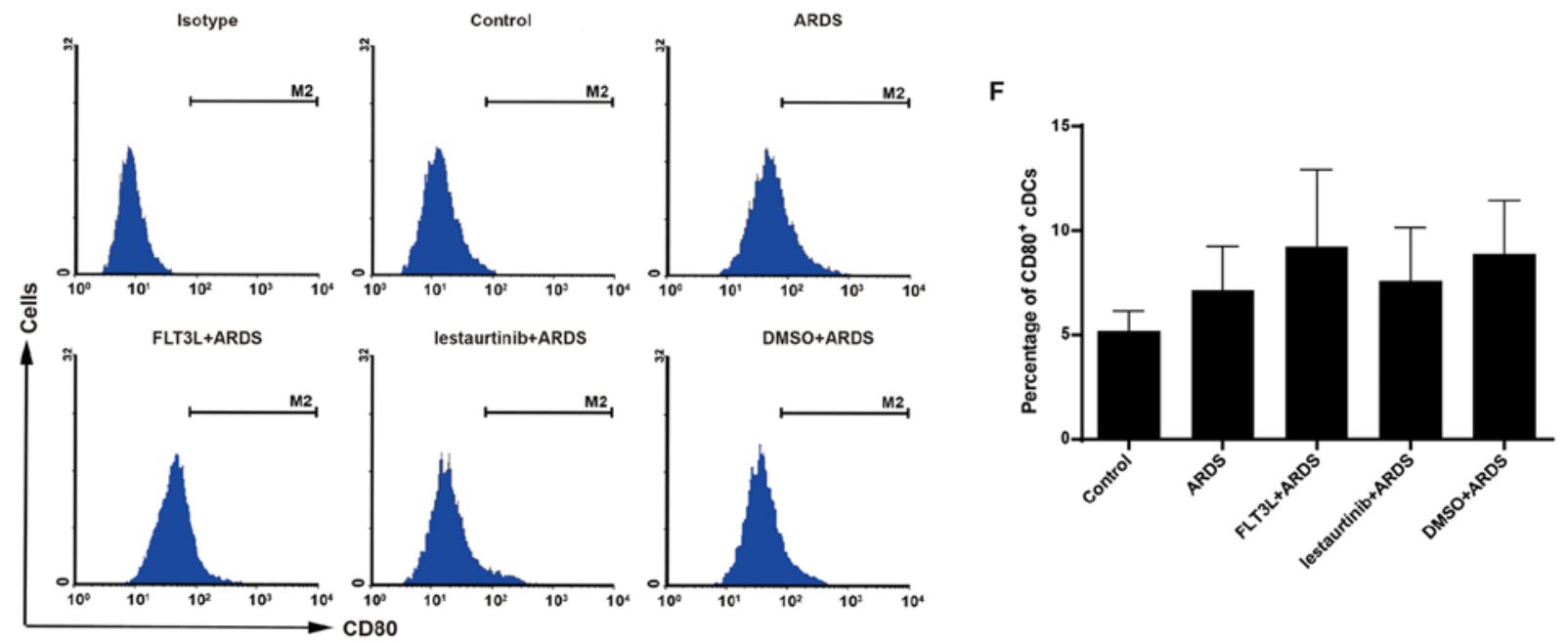

Figure 3. Effect of FLT3 signaling on the aggregation and maturation of pulmonary cDCs. The aggregation and maturation of pulmonary cDCs were measured by flow cytometry at $6 \mathrm{~h}$ post-LPS challenge. (A) Representative dot plots and (B) quantification showing the percentage of $\mathrm{cDCs}\left(\mathrm{CD} 11 \mathrm{c}^{+} \mathrm{CD} 11 \mathrm{~b}^{+}\right)$among total lung cells in the experimental groups. (C) Representative histograms and (D) quantification showing the expression of MHC II in pulmonary cDCs in the experimental groups. (E) Representative histograms and (F) quantification showing the expression of CD80 in pulmonary cDCs in the experimental groups. Data are presented as the mean \pm standard deviation $(n=6)$. ${ }^{*} \mathrm{P}<0.05$ vs. Control; ${ }^{\#} \mathrm{P}<0.05$ vs. ARDS; ${ }^{\star} \mathrm{P}<0.05$ vs. FLT3L+ARDS; and ${ }^{\$} \mathrm{P}<0.05$ vs. lestaurtinib+ARDS. FLT3, Fms-like tyrosine kinase 3; cDCs, classical dendritic cells; LPS, lipopolysaccharide; MHC II, major histocompatibility complex class II; ARDS, acute respiratory distress syndrome; FLT3L, Fms-like tyrosine kinase 3-ligand.

cDCs compared with the ARDS alone group (Fig. 3C and D). Furthermore, compared with the DMSO+ARDS group, the lestaurtinib+ARDS group exhibited decreased expression of
MHC II in pulmonary cDCs (Fig. 3C and D). However, the expression of CD80 in pulmonary cDCs exibited no significant difference among the groups (Fig. 3E and F). 
A

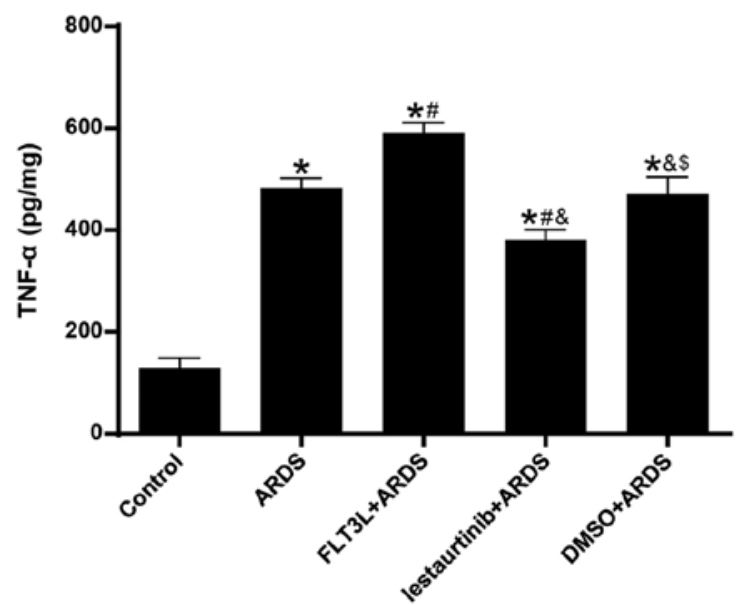

B

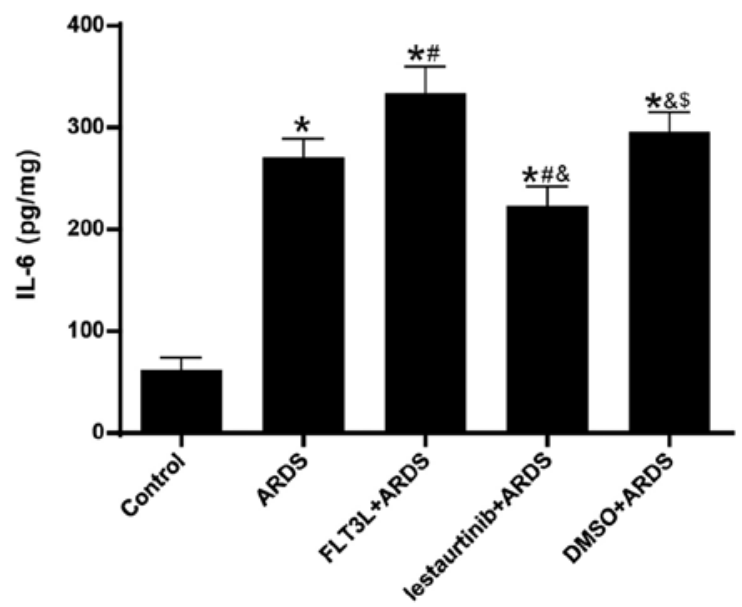

Figure 4. Effect of cDC manipulation on acute lung inflammation in ARDS. (A) Levels of TNF- $\alpha$ and (B) IL-6 were measured using ELISA to evaluate acute lung inflammation at $6 \mathrm{~h}$ post-LPS challenge. Data are presented as the mean \pm standard deviation $(\mathrm{n}=6)$. ${ }^{*} \mathrm{P}<0.05 \mathrm{vs}$. Control; ${ }^{\#} \mathrm{P}<0.05 \mathrm{vs}$. ARDS; ${ }^{*} \mathrm{P}<0.05 \mathrm{vs}$. FLT3L+ARDS; and ${ }^{\$} \mathrm{P}<0.05$ vs. lestaurtinib+ARDS. cDC, classical dendritic cell; ARDS, acute respiratory distress syndrome; TNF, tumor necrosis factor; IL, interleukin; LPS, lipopolysaccharide; FLT3L, Fms-like tyrosine kinase 3-ligand.

Effect of cDC manipulation on acute lung inflammation. The levels of TNF- $\alpha$ and IL- 6 in the lungs at $6 \mathrm{~h}$ following LPS challenge were measured, in order to evaluate acute lung inflammation. The results demonstrated that the levels of both TNF- $\alpha$ and IL- 6 were significantly increased in the ARDS group compared with the control group (Fig. 4). FLT3L pretreatment in the FLT3L+ARDS group significantly increased the TNF- $\alpha$ and IL- 6 levels in the lung compared with the ARDS alone group (Fig. 4). Additionally, lestaurtinib pretreatment in the lestaurtinib+ARDS group significantly decreased the TNF- $\alpha$ and IL- 6 levels compared with the DMSO+ARDS group (Fig. 4).

Effect of cDC manipulation on lung injuries and lung edema. The lung injury score was calculated next. The histopathological analysis showed alveolar wall thickening, diffused infiltration of inflammatory cells, hemorrhage, intra-alveolar exudates and edema in the ARDS group at $6 \mathrm{~h}$ and $24 \mathrm{~h}$ following LPS challenge (Fig. 5A and B), with an elevated lung injury score (Fig. 5C and D). The pathologic changes were markedly aggravated (Fig. 5A and B) and the lung injury was significantly increased (Fig. 5C and D) in the FLT3L+ARDS group compared with the ARDS alone group. By contrast, lestaurtinib pretreatment in the lestaurtinib+ARDS group greatly alleviated the pathologic changes (Fig. 5A and B) and significantly decreased the lung injury score (Fig. 5C and B) compared with the DMSO+ARDS group.

The LWW/BW ratio was calculated to evaluate lung edema. The LWW/BW ratio in the ARDS group was significantly increased at $6 \mathrm{~h}$ and $24 \mathrm{~h}$ following LPS challenge compared with the control group (Fig. 5E and F). The LWW/BW ratio in the FLT3L+ARDS group was further increased compared with the ARDS alone group (Fig. 5E and F). By contrast, the LWW/BW ratio in the lestaurtinib+ARDS group was significantly decreased compared with the DMSO+ARDS group (Fig. 5E and F).

Effect of cDC manipulation on neutrophil infiltration. MPO activity was assessed to evaluate neutrophil infiltration in the lung. The results demonstrated that, compared with the control group, lung MPO activity in the ARDS group was increased significantly at $6 \mathrm{~h}$ and $24 \mathrm{~h}$ following LPS challenge (Fig. 6). FLT3L pretreatment in the FLT3L+ARDS group further augmented MPO activity compared with the ARDS alone group (Fig. 6). By contrast, lestaurtinib pretreatment in the lestaurtinib+ARDS group significantly decreased MPO activity compared with the DMSO+ARDS group (Fig. 6).

Effect of cDC manipulation on the balance of the Th1/Th2 response. The mRNA and protein expression levels of T-bet and GATA-3 were measured in order to evaluate the balance of the Th1/Th2 response. Since it has been demonstrated that mobilized DCs appear in draining lymph nodes at least $6 \mathrm{~h}$ after the invasion of antigens (27), mRNA and protein expression of T-bet and GATA-3 were measured at $24 \mathrm{~h}$ following LPS challenge, instead of at $6 \mathrm{~h}$. The results demonstrated that LPS challenge in the ARDS group led to significant elevation of $\mathrm{mRNA}$ and protein expression of T-bet (Fig. 7A, C and D), but not GATA-3 (Fig. 7B, C and E) in the lung, indicating a Th1-biased response. FLT3L pretreatment in the FLT3L+ARDS group further amplified this effect (Fig. 7A-E). By contrast, lestaurtinib pretreatment in the lestaurtinib+ARDS group significantly decreased the mRNA and protein expression levels of T-bet, but not GATA-3, in the lung compared with the DMSO+ARDS group (Fig. 7A-E), indicating a Th2-biased response.

Effect of cDC manipulation on Th1/Th2 cytokine production. The concentrations of IFN- $\gamma /$ IL- $1 \beta$ and IL-4/IL-10 in the lungs at $24 \mathrm{~h}$ following LPS challenge were measured in order to evaluate the Th1 and Th2 cytokine production, respectively. The results demonstrated that the concentration of IFN- $\gamma$ and IL-1 $\beta$ in the lungs was significantly increased in the ARDS group compared with the control group (Fig. 8A and B), indicating an enhanced Th1-skewed cytokine pattern. FLT3L pretreatment in the FLT3L+ARDS group further increased the concentration of IFN- $\gamma$ and IL-1 $\beta$ compared with the ARDS 
A

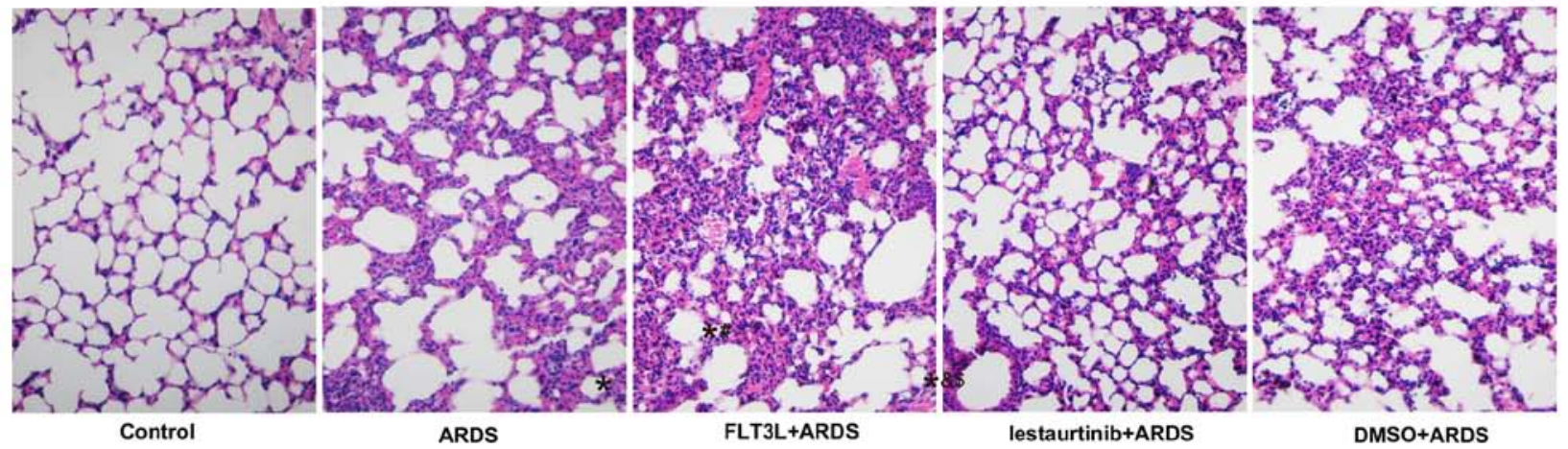

B

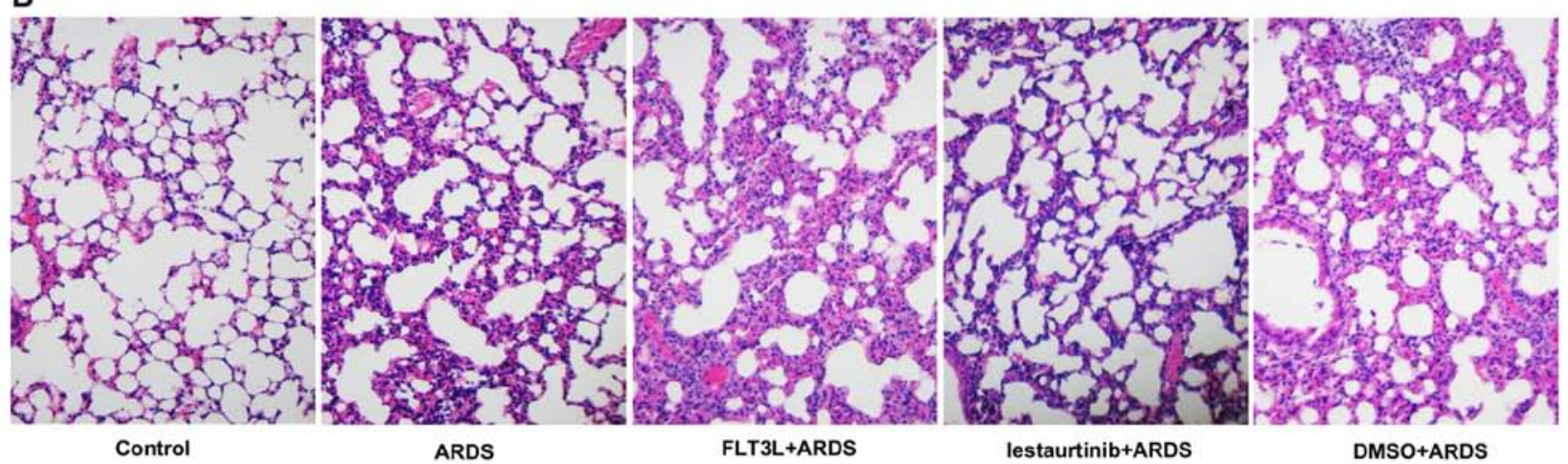

C

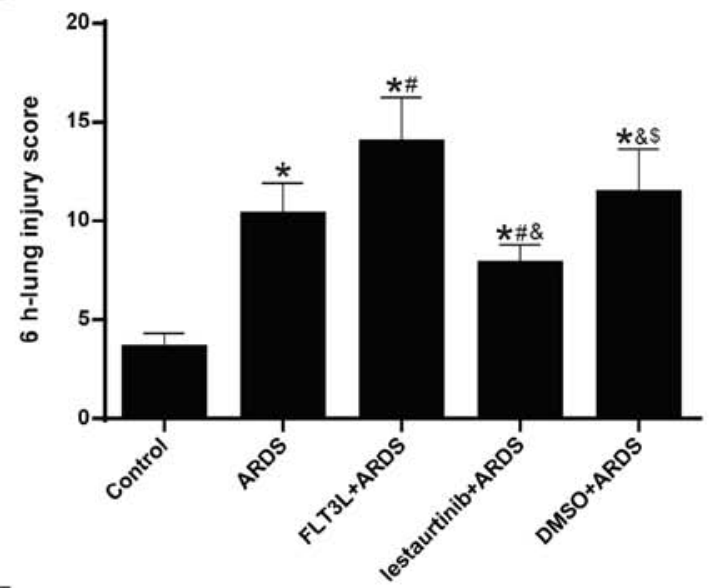

E

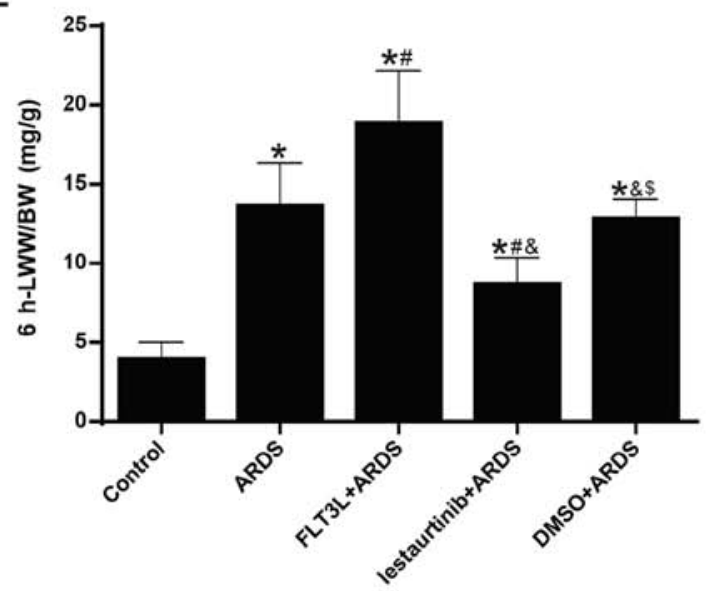

D

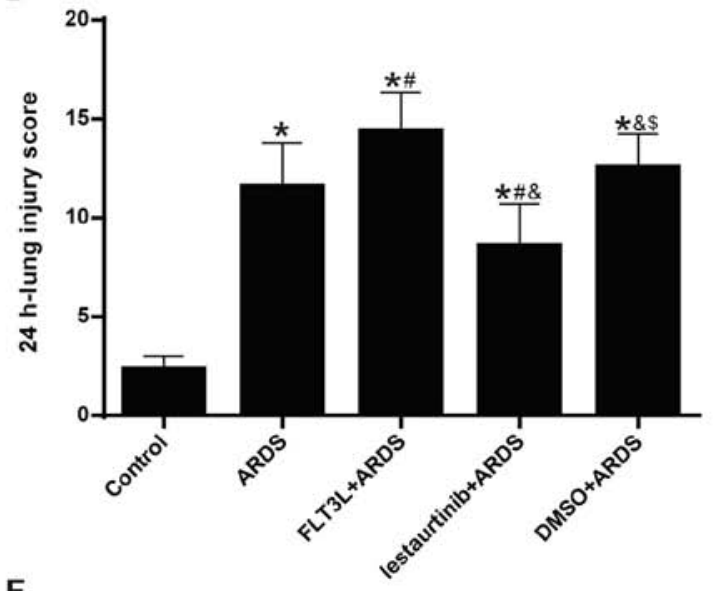

$\mathbf{F}$

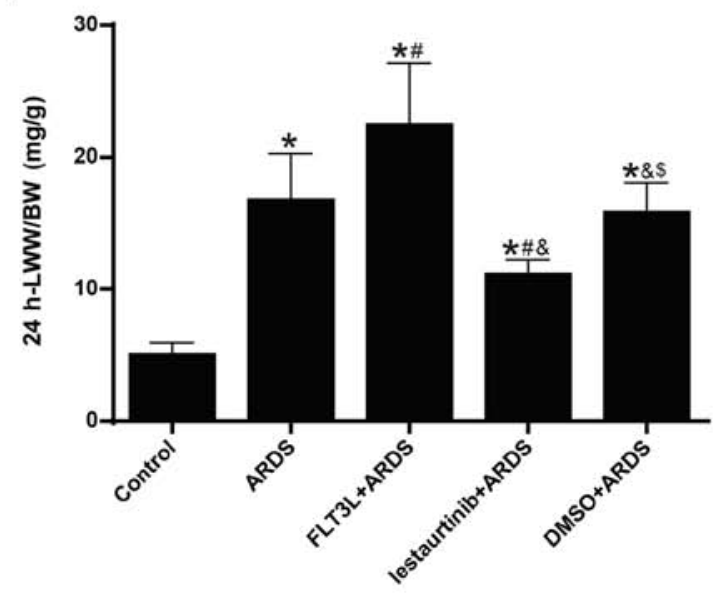

Figure 5. Effect of cDC manipulation on lung edema and lung injury. LWW/BW and the lung injury score were measured to assess lung edema and lung injury at 6 and $24 \mathrm{~h}$ post-LPS challenge, respectively. (A) Hematoxylin and eosin staining (magnification, x200) of lung tissues at $6 \mathrm{~h}$ and (B) at $24 \mathrm{~h}$ post-LPS challenge. (C) Lung injury score at $6 \mathrm{~h}$ and (D) at $24 \mathrm{~h}$ post-LPS challenge. (E) LWW/BW at $6 \mathrm{~h}$ and (F) at $24 \mathrm{~h}$ post-LPS challenge. Lung injury score is expressed as arbitrary mean units. Data are presented as the mean \pm standard deviation $(n=6)$. ${ }^{*} \mathrm{P}<0.05$ vs. Control; ${ }^{*} \mathrm{P}<0.05$ vs. ARDS; ${ }^{\circledR} \mathrm{P}<0.05$ vs. FLT3L+ARDS; and ${ }^{\$} \mathrm{P}<0.05$ vs. lestaurtinib+ARDS. cDC, classical dendritic cell; LWW/BW, lung wet weight to body weight; LPS, lipopolysaccharide; ARDS, acute respiratory distress syndrome; FLT3L, Fms-like tyrosine kinase 3-ligand. 
A

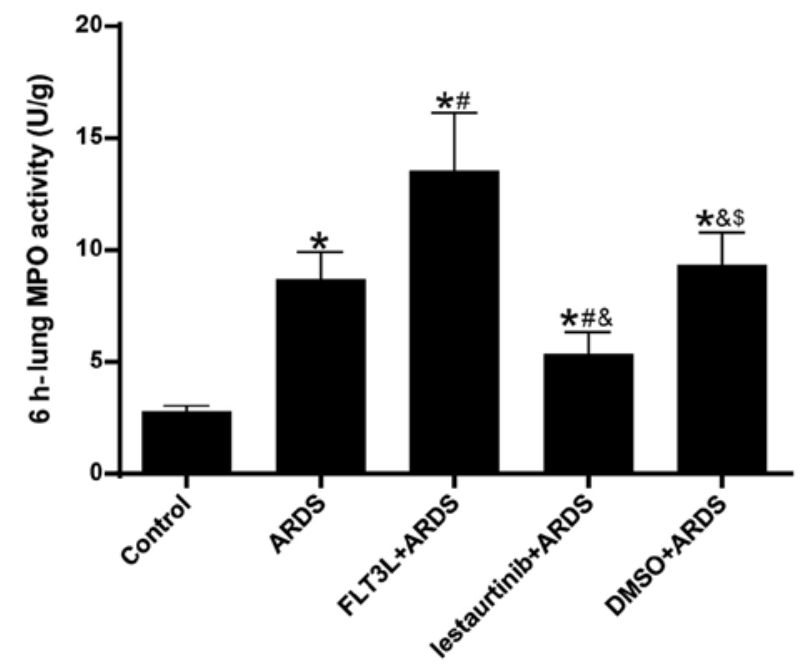

B

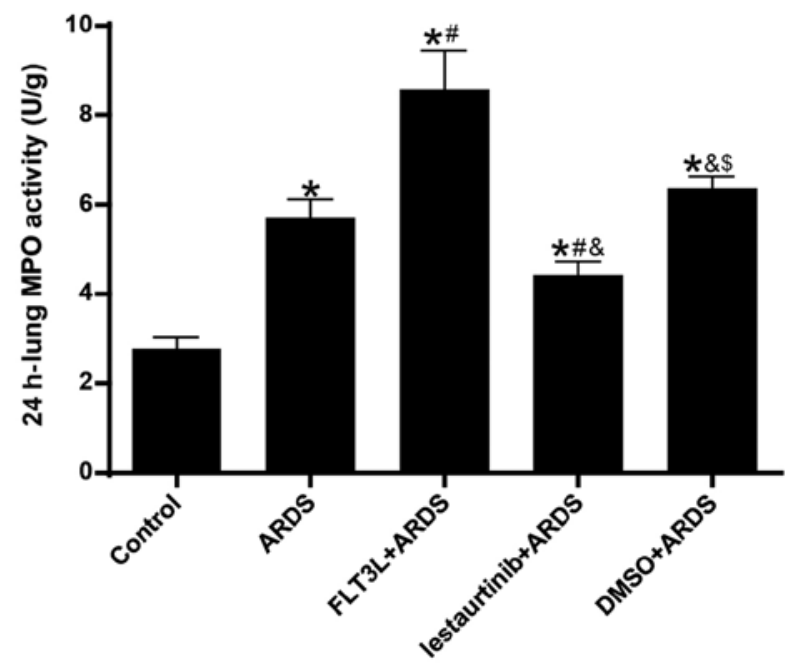

Figure 6. Effect of cDC manipulation on neutrophil infiltration. MPO activity was measured by chromometry to assess neutrophil infiltration (A) at 6 h and (B) at $24 \mathrm{~h}$ post-LPS challenge. MPO activity is expressed as units per gram of sample. Data are presented as the mean \pm standard deviation ( $=6$ ). $\mathrm{P}<0.05$ vs. Control; ${ }^{\#} \mathrm{P}<0.05$ vs. ARDS; ${ }^{\circledR} \mathrm{P}<0.05$ vs. FLT3L+ARDS; ${ }^{\$} \mathrm{P}<0.05$ vs. lestaurtinib+ARDS. cDC, classical dendritic cell; MPO, myeloperoxidase; LPS, lipopolysaccharide; ARDS, acute respiratory distress syndrome; FLT3L, Fms-like tyrosine kinase 3-ligand.

A

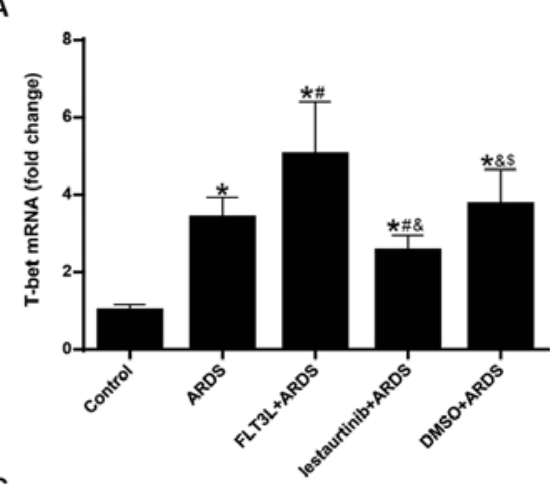

C

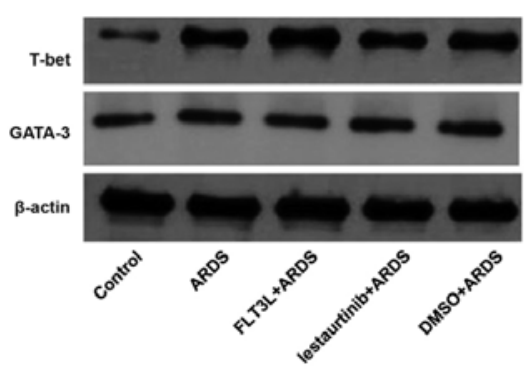

B
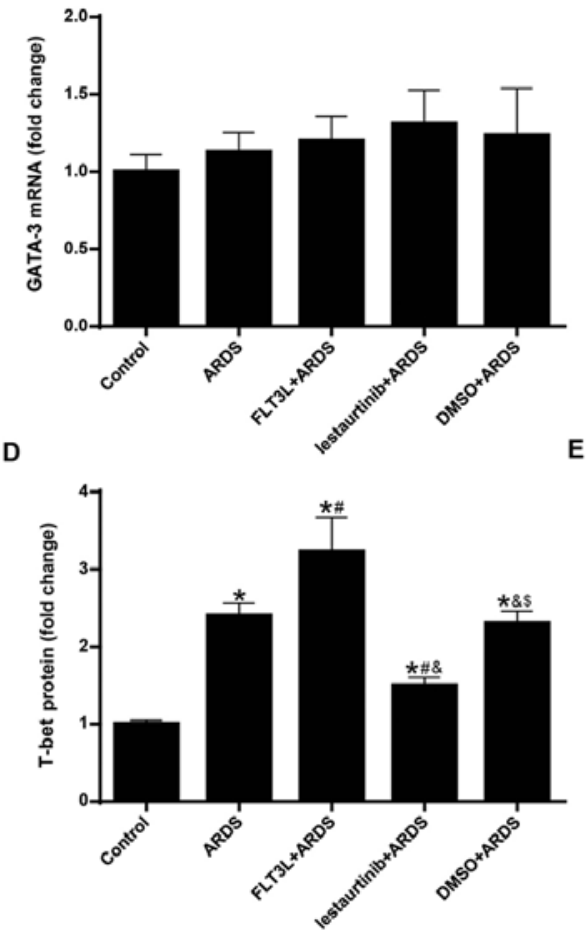

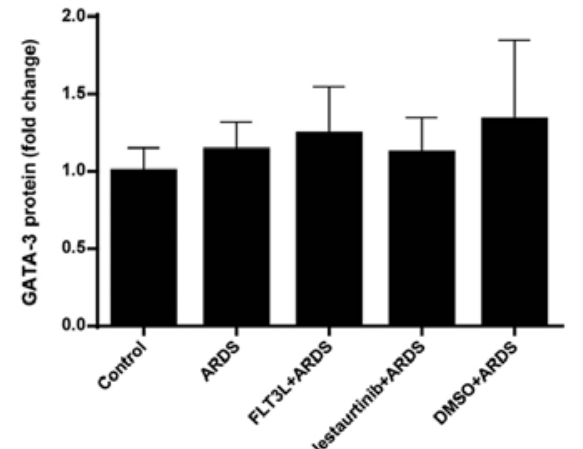

Figure 7. Effect of cDC manipulation on the balance of the Th1/Th2 response. The mRNA and protein expression levels of T-bet and GATA-3 were measured by reverse transcription-quantitative PCR and western blotting to evaluate the balance of the Th1/Th2 response. (A) mRNA expression of T-bet and (B) GATA-3. $\beta$-actin was used as a reference gene. (C) Representative blots from western blotting analysis of T-bet and GATA-3 protein expression. (D) Protein expression levels of T-bet and (E) GATA-3. $\beta$-actin was used as a reference protein. Data are presented as the mean \pm standard deviation $(\mathrm{n}=3)$. ${ }^{*} \mathrm{P}<0.05 \mathrm{vs}$. Control; ${ }^{\#} \mathrm{P}<0.05$ vs. ARDS; ${ }^{\circledR}$ P<0.05 vs. FLT3L+ARDS; and ${ }^{\$} \mathrm{P}<0.05$ vs. lestaurtinib+ARDS. cDC, classical dendritic cell; Th, T helper cell; T-bet, T-box-expressed-in-T-cells; GATA-3, GATA binding protein 3; ARDS, acute respiratory distress syndrome; FLT3L, Fms-like tyrosine kinase 3-ligand.

alone group (Fig. 8A and B). By contrast, lestaurtinib pretreatment in the lestaurtinib+ARDS group significantly decreased the concentration of IFN- $\gamma$ and IL- $1 \beta$ in the lung compared with the DMSO+ARDS group, indicating a repression of the Th1-skewed cytokine pattern (Fig. 8A and B). Unexpectedly, neither LPS challenge nor cDC manipulation affected the concentration of IL-4 and IL-10 in the lungs among all groups (Fig. 8C and D), indicating a steady Th2 cytokine pattern (Fig. 8B).

Increased expression of FLT3L in ARDS lung tissue. The protein expression of FLT3L was measured in normal and 
A

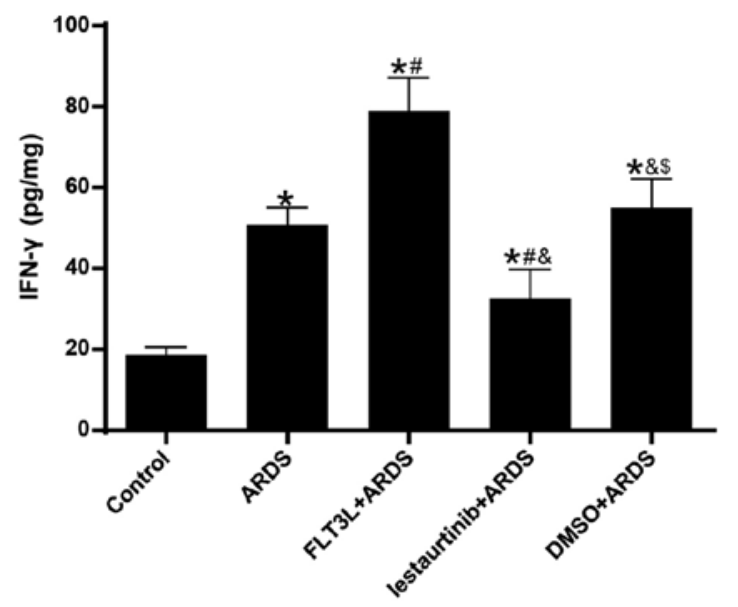

C

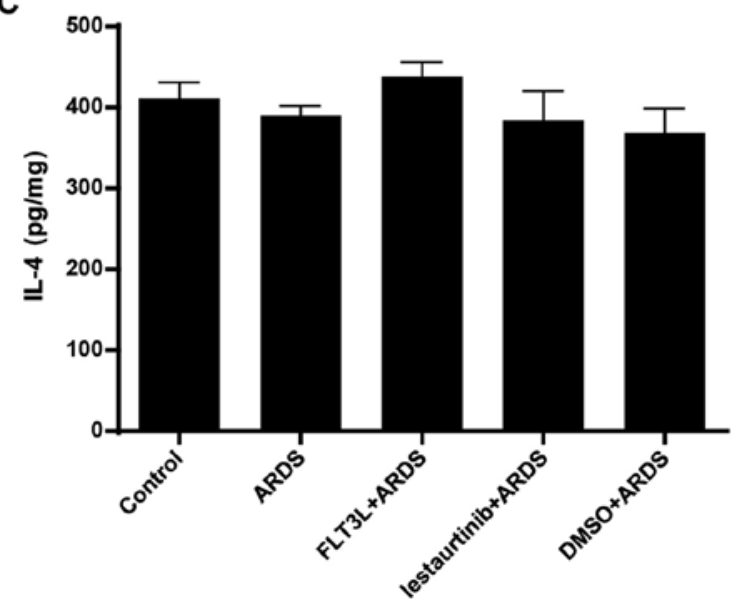

B

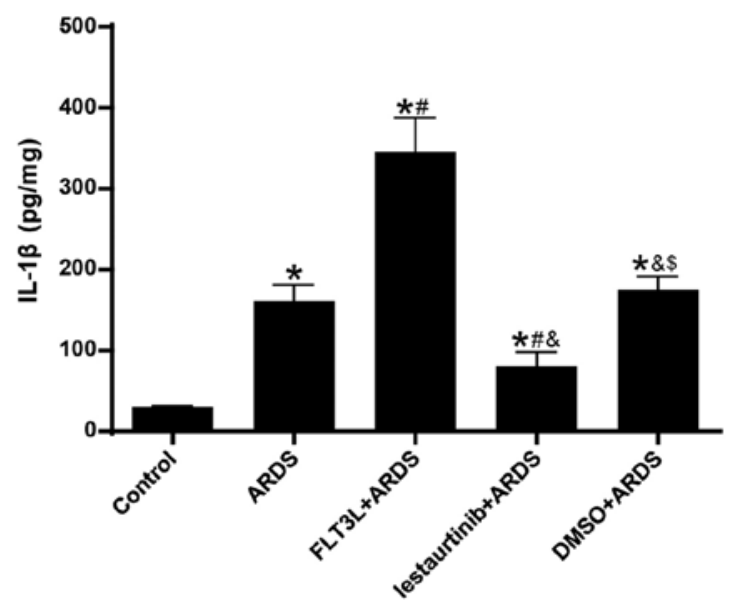

D

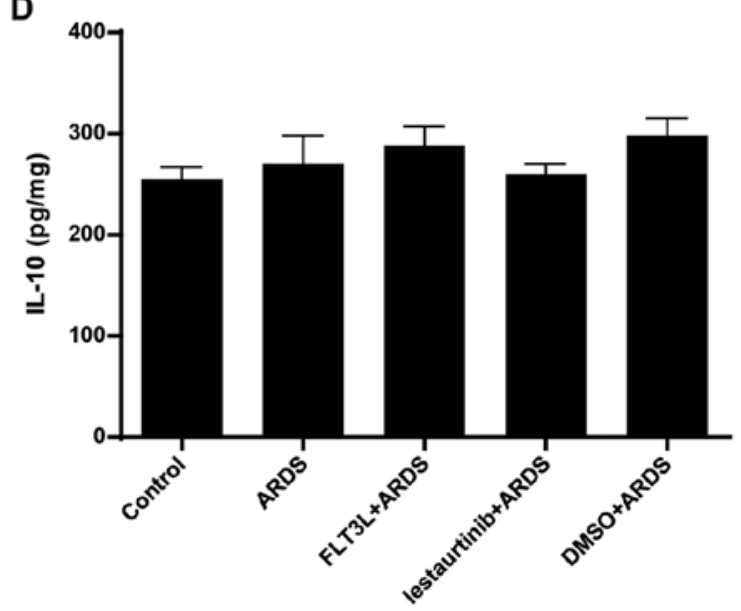

Figure 8. Effect of cDC manipulation on Th1/Th2 cytokine production. (A) Levels of IFN- $\gamma$, (B) IL-1 $\beta$, (C) IL-4 and (D) IL-10 were measured in the lungs by ELISA at $24 \mathrm{~h}$ post-LPS challenge, in order to evaluate the Th1/Th2 cytokine production. Data are presented as the mean \pm standard deviation ( $\mathrm{n}=6$ ). ${ }^{\text {"P }}<0.05$ vs. Control; " $\mathrm{P}<0.05$ vs. ARDS; ${ }^{\&} \mathrm{P}<0.05$ vs. FLT3L+ARDS; and ${ }^{\mathrm{S}} \mathrm{P}<0.05$ vs. lestaurtinib+ARDS. cDC, classical dendritic cell; Th, T helper cell; IFN, interferon; IL, interleukin; LPS, lipopolysaccharide; ARDS, acute respiratory distress syndrome; FLT3L, Fms-like tyrosine kinase 3-ligand.
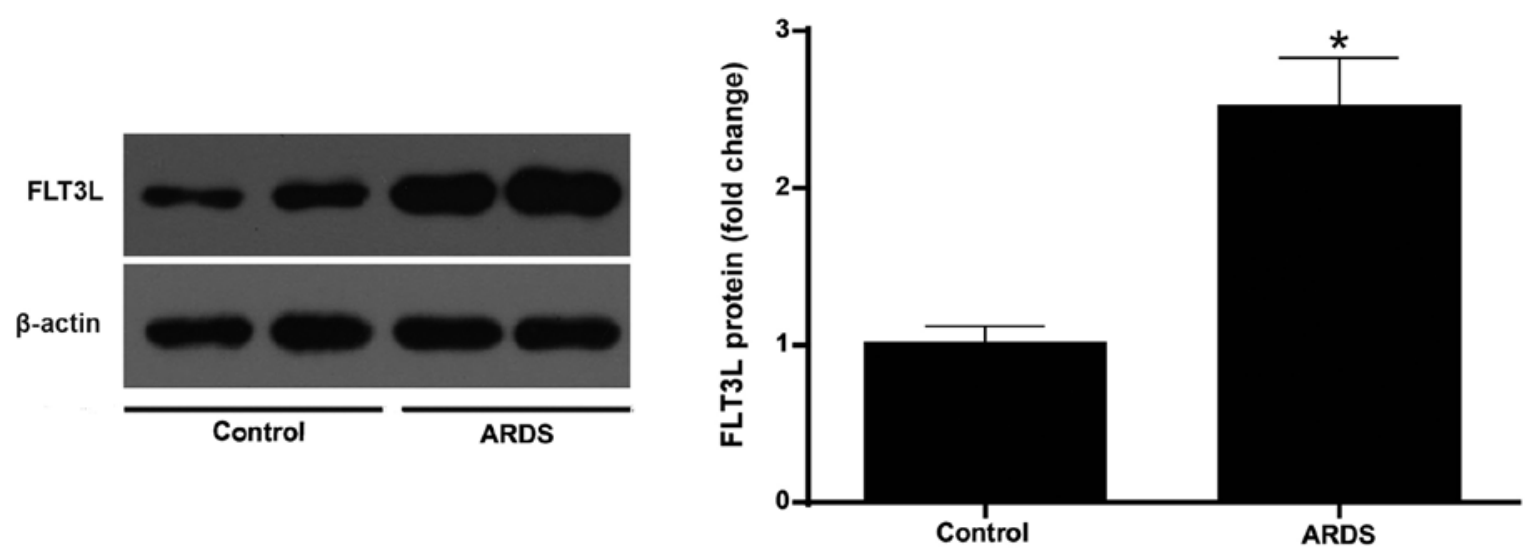

Figure 9. FLT3L expression in normal and ARDS lung tissues. FLT3L protein expression levels in normal and ARDS lung tissues were evaluated by western blotting at $6 \mathrm{~h}$ post-LPS challenge. Data are presented as the mean \pm standard deviation $(\mathrm{n}=3)$. " $\mathrm{P}<0.05$ vs. Control. FLT3L, Fms-like tyrosine kinase 3 -ligand; ARDS, acute respiratory distress syndrome.

ARDS lung tissue at $6 \mathrm{~h}$ following LPS challenge. The results demonstrated that the LPS challenge led to a significantly higher expression of FLT3L in the ARDS lung tissues compared with the control normal lung tissues (Fig. 9).

\section{Discussion}

The development of ARDS is characterized by the sequestration of activated neutrophils and monocytes/macrophages, 
inducing delayed apoptosis and an increased respiratory burst, which results in the devastation of the pulmonary epithelium and disruption of the blood-air barrier (1). The present study described the involvement of pulmonary cDCs in the pathogenesis of ARDS. The results demonstrated that pulmonary cDCs regulated acute lung inflammation and injury in an ARDS model, favoring the Th1 response and enhancing neutrophil infiltration, which may constitute the underlying mechanisms for the contribution of pulmonary cDCs to acute lung inflammation and injury in LPS-induced ARDS.

It has been generally accepted that ARDS primarily represents uncontrolled inflammation of the lung $(1,3)$. Pulmonary cDCs act as sentinels and key elements in the immune network of the lung, and cDCs have recently been reported to modulate the progression of inflammation in several pulmonary inflammatory disorders $(5,6)$; however, their distinctive role in the pathogenesis of ARDS has yet to be elucidated. Therefore, the present study investigated the aggregation and maturation status of pulmonary cDCs during the initial $24 \mathrm{~h}$ period of LPS-induced ARDS. Although several studies have reported that pulmonary cDCs aggregate and mature in the case of ARDS $(26,32)$, the present results highlighted that the aggregation and maturation of pulmonary cDCs peaked as early as $6 \mathrm{~h}$ following LPS challenge. Both the concentration of TNF- $\alpha$ and IL-6, two indicators of acute lung inflammation, were elevated in parallel with the aggregation and maturation of pulmonary DCs. Additionally, the present results demonstrated that the aggregation and maturation of pulmonary cDCs decreased sharply to a level almost comparable to that of normal control mice just $24 \mathrm{~h}$ following LPS challenge, implying that pulmonary cDCs mainly function during the early stage of ARDS. Together, these results suggested that pulmonary cDCs may, at least in part, initiate acute lung inflammation in ARDS.

cDCs have also been reported to manage the progression of inflammation in multiple pulmonary and non-pulmonary diseases $(23,33)$. Consistent with observations from other inflammatory disorders (34), the present study demonstrated that, along with the increased aggregation and maturation of pulmonary cDCs, acute lung inflammation and histopathologic injury were also exacerbated. By contrast, inhibited aggregation and maturation of pulmonary cDCs by lestaurtinib was associated with an improvement in acute lung inflammation and injury. Therefore, the present findings indicated the regulatory role of pulmonary cDCs in the case of ARDS.

Since FLT3 signaling is one of the primary pathways that controls the development and behavior of cDCs, including differentiation, migration, aggregation, maturation and even apoptosis (35), FLT3 signaling was recently employed as a specific and efficient tool for cDC manipulation under several inflammatory conditions $(9,13,36,37)$. The present study also took advantage of the cDC-targeting property of FLT3 signaling in ARDS. As expected, the results revealed that FLT3L pretreatment resulted in significantly increased aggregation and maturation of cDCs, while blocking FLT3 signaling with lestaurtinib inhibited aggregation and maturation of cDCs. These observations suggested that FLT3 signaling may be a promising pathway for the manipulation of $\mathrm{cDCs}$ in vivo.

As one of the most important antigen-presenting cells (APCs), cDCs are generally recognized as a bridge linking innate and adaptive immune responses (5). Previous studies have suggested that cDCs determine the ensuing immune response via multiple mechanisms, such as shifting the balance of the Th1/Th2 response, secreting pro-inflammatory cytokines, and affecting innate immune elements $(16,38,39)$. Thus, the present study investigated the mechanisms through which cDCs may affect LPS-induced acute lung inflammation and injury. The present results demonstrated that modulation of FLT3 signaling was associated with altered aggregation and maturation of pulmonary DCs, as well as a shifted the balance of the Th1/Th2 response and ensuing cytokine production. Emerging data also suggest an underlying role of FLT3 signaling in the modulation of the inflammatory process $(40,41)$. Furthermore, in vitro administration of lestaurtinib only decreases the cDC population and activation, but not $\mathrm{T}$ cell aggregation or activation (9). Together, these results suggest that FLT3 signaling directly regulates the aggregation and maturation of pulmonary cDCs, which in turn shifts the balance of the Th1/Th2 response and ensuing cytokine production.

Regulating neutrophil infiltration may be another mechanism by which cDCs regulate LPS-induced acute lung inflammation and injury. Neutrophils are the key elements of innate immunity, and neutrophil infiltration serves a critical role in the development of ARDS. Neutrophils are considered to be the first mobilized cellular element in the pathogenesis of ARDS $(42,43)$. However, recent studies have demonstrated that pulmonary cDCs may aggregate before the infiltration of neutrophils (44). In vitro studies have demonstrated that cDCs not only enhance the chemotaxis of neutrophils, but also protect neutrophils from apoptosis $(45,46)$. The results from the present study are consistent with these previous results.

Finally, the present results demonstrated that the expression of FLT3L, a dedicated activator for FLT3 signaling, was higher in ARDS lung tissue compared with normal lung tissue. These findings suggested that the FLT3L-induced activation of FLT3 signaling during ARDS may be protective or self-reparative (44), which provided a rationale for DC-targeting therapy in ARDS.

It may be argued that cDCs may not be the only APCs responsible for immunity or tolerance in the lung. Indeed, plasmacytoid CD11c ${ }^{+} \mathrm{CD} 11 \mathrm{~b}-\mathrm{B} 220^{+} \mathrm{Gr}-1^{+} \mathrm{DCs}$ (pDCs) have been demonstrated to downregulate the production of inflammatory cytokines in the lung, thus attenuating lung injury in experimental ARDS (26). However, pDCs account for $<5 \%$ of the total pulmonary DC population and are only found within the bronchial epithelium (5); their effect on the pulmonary immune microenvironment is negligible compared with that of cDCs. However, the distinctive role of pDCs in the pathogenesis of ARDS deserves further investigation.

Of note, the results on CD80 expression on pulmonary cDCs in the present study were unexpected. Neither LPS nor FLT3 signaling altered the cell-surface expression of CD80 in pulmonary cDCs at $6 \mathrm{~h}$ following LPS challenge. One possible explanation is that in most APC populations, the peak expression of both costimulatory molecules (CD80 and CD86) occurs at least $18 \mathrm{~h}$ following LPS challenge, and CD80 is expressed only inducibly and later than CD86 $(47,48)$. Therefore, the $6 \mathrm{~h}$ observation period used in the present study may have been too short to detect changes in CD80 expression. 
Another limitation arises from the imbalance of the Th1/Th2 skewed cytokine profiles in the lung. Although the production of IFN- $\gamma$ and IL- $1 \beta$ varied consistently with the relative expression of T-bet, the concentration was fairly low at $24 \mathrm{~h}$ following LPS challenge. Since the strong antigen-presenting activity between DCs and T cells in draining lymph nodes occurs at least $24 \mathrm{~h}$ after insult, it is reasonable that the concentration of IFN- $\gamma$ and IL-1 $\beta$ in the lung fluctuated in the low range at $24 \mathrm{~h}$ after LPS challenge (49). In addition, pulmonary IL-4 and IL-10 exhibited comparable concentrations, which were much higher than those of IFN- $\gamma$ and IL- $1 \beta$. Previous studies have proposed that under steady-state conditions, an inherently Th2-biased response predominates in lung parenchyma, providing a counteraction to potentially tissue-damaging Th1 responses induced by innocuous inhaled antigens (5). The increased concentrations of IL-4 and IL-10 may thus reflect the inherently $\mathrm{Th} 2$-biased response.

In conclusion, the present results highlighted that pulmonary cDCs regulated acute lung inflammation and injury in LPS-induced ARDS and revealed that pulmonary cDCs modulated LPS-induced acute lung inflammation and injury through the manipulation of neutrophil infiltration and balance of the Th1/Th2 response. The present study demonstrated that inhibition of FLT3 signaling by lestaurtinib attenuated acute lung injury, providing a novel perspective for the prevention and treatment of ARDS. However, clinical trials are required for the confirmation and translation of the present research results in patients.

\section{Acknowledgments}

Not applicable.

\section{Funding}

The present study was supported by the National Natural Science Foundation of China (grant no. 81400054), the Natural Science Foundation of Jiangsu Province (grant no. BK20140122), the Talented Youth Program of Jiangsu Province (grant no. QNRC2017179) and the 333 High Level Talent Training Project of Jiangsu Province (grant no. 2018III-0299).

\section{Availability of data and materials}

All data generated or analyzed during this study are included in this article.

\section{Authors' contributions}

LL and LD conceived and designed the study. LL, LD, DZ and FG performed the experiments, analyzed the data, and interpreted the results. LD, FG and JY generated the figures and drafted the manuscript. All authors have read and approved the final manuscript.

\section{Ethics approval and consent to participate}

The experimental protocols were approved by the Institutional Animal Care and Use Committee at Nanjing Medical University (approval no. LLSP201607155). All animal experiments were conducted in accordance with the National Institutes of Health Guidance for the Care and Use of Laboratory Animals.

\section{Patient consent for publication}

Not applicable.

\section{Competing interests}

The authors declare that they have no competing interests.

\section{References}

1. Thompson BT, Chambers RC and Liu KD: Acute respiratory distress syndrome. N Engl J Med 377: 562-572, 2017.

2. Fan E, Brodie D and Slutsky AS: Acute respiratory distress syndrome: Advances in diagnosis and treatment. JAMA 319: 698-710, 2018

3. Reilly JP, Christie JD and Meyer NJ: Fifty years of research in ARDS. Genomic contributions and opportunities. Am J Respir Crit Care Med 196: 1113-1121, 2017.

4. ARDS Definition Task Force, Ranieri VM, Rubenfeld GD, Thompson BT, Ferguson ND, Caldwell E, Fan E, Camporota L and Slutsky AS: Acute respiratory distress syndrome: The Berlin Definition. JAMA 307: 2526-2533, 2012.

5. Kumar V: Dendritic cells in sepsis: Potential immunoregulatory cells with therapeutic potential. Mol Immunol 101: 615-626, 2018.

6. Lambrecht BN and Hammad H: The role of dendritic and epithelial cells as master regulators of allergic airway inflammation. Lancet 376: 835-843, 2010.

7. Buttignol M, Pires-Neto RC, Rossi E Silva RC, Albino MB Dolhnikoff $M$ and Mauad T: Airway and parenchyma immune cells in influenza A(H1N1)pdm09 viral and non-viral diffuse alveolar damage. Respir Res 18: 147, 2017.

8. von Wulffen W, Steinmueller M, Herold S, Marsh LM, Bulau P, Seeger W, Welte T, Lohmeyer J and Maus UA: Lung dendritic cells elicited by Fms-like tyrosine 3-kinase ligand amplify the lung inflammatory response to lipopolysaccharide. Am J Respir Crit Care Med 176: 892-901, 2007.

9. Whartenby KA, Calabresi PA, McCadden E, Nguyen B, Kardian D, Wang T, Mosse C, Pardoll DM and Small D: Inhibition of FLT3 signaling targets DCs to ameliorate autoimmune disease. Proc Natl Acad Sci USA 102: 16741-16746, 2005.

10. Lau CM, Nish SA, Yogev N, Waisman A, Reiner SL and Reizis B: Leukemia-associated activating mutation of Flt3 expands dendritic cells and alters T cell responses. J Exp Med 213: 415-431, 2016.

11. Kim SW, Choi SM, Choo YS, Kim IK, Song BW and Kim HS: Flt3 ligand induces monocyte proliferation and enhances the function of monocyte-derived dendritic cells in vitro. J Cell Physiol 230: 1740-1749, 2015

12. Sato T, Yang X, Knapper S, White P, Smith BD, Galkin S, Small D, Burnett A and Levis M: FLT3 ligand impedes the efficacy of FLT3 inhibitors in vitro and in vivo. Blood 117: 3286-3293, 2011.

13. Dong L, He H, Liu J, Liu L, Yang Y and Qiu H: The control effects of FLT3 signaling-dependent pulmonary conventional dendritic cells on the initiation of acute lung inflammation response to lipopolysaccharide induced acute lung injury in mice. Zhonghua Ji Zhen Yi Xue Za Zhi 25: 1412-1417, 2016 (In Chinese).

14. Mellman I: Dendritic cells: Master regulators of the immune response. Cancer Immunol Res 1: 145-149, 2013.

15. Shao Z, Bharadwaj AS, McGee HS, Makinde TO and Agrawal DK: Fms-like tyrosine kinase 3 ligand increases a lung DC subset with regulatory properties in allergic airway inflammation. J Allergy Clin Immunol 123: 917-924 e2, 2009.

16. Ludwig IS, Geijtenbeek TB and van Kooyk Y: Two way communication between neutrophils and dendritic cells. Curr Opin Pharmacol 6: 408-413, 2006.

17. Dieker J, Tel J, Pieterse E, Thielen A, Rother N, Bakker M, Fransen J, Dijkman HB, Berden JH, de Vries JM, et al: Circulating apoptotic microparticles in systemic lupus erythematosus patients drive the activation of dendritic cell subsets and prime neutrophils for NETosis. Arthritis Rheumatol 68: 462-472, 2016. 
18. Baudiß K, de Paula Vieira R, Cicko S, Ayata K, Hossfeld M, Ehrat N, Gómez-Muñoz A, Eltzschig HK and Idzko M: C1P attenuates lipopolysaccharide-induced acute lung injury by preventing NF- $\mathrm{KB}$ activation in neutrophils. J Immunol 196: 2319-2326, 2016.

19. McWilliam AS, Nelson D, Thomas JA and Holt PG: Rapid dendritic cell recruitment is a hallmark of the acute inflammatory response at mucosal surfaces. J Exp Med 179: 1331-1336, 1994.

20. Olguín-Alor R, de la Fuente-Granada M, Bonifaz LC, Antonio-Herrera L, García-Zepeda EA and Soldevila G: A key role for inhibins in dendritic cell maturation and function. PLoS One 11: e0167813, 2016

21. Schlosser K, Taha M, Deng Y, McIntyre LA, Mei SHJ and Stewart DJ: High circulating angiopoietin-2 levels exacerbate pulmonary inflammation but not vascular leak or mortality in endotoxin-induced lung injury in mice. Thorax 73: 248-261, 2018.

22. Aggarwal NR, King LS and D'Alessio FR: Diverse macrophage populations mediate acute lung inflammation and resolution. Am J Physiol Lung Cell Mol Physiol 306: L709-L725, 2014.

23. Wen H, Hogaboam CM, Gauldie J and Kunkel SL: Severe sepsis exacerbates cell-mediated immunity in the lung due to an altered dendritic cell cytokine profile. Am J Pathol 168: 1940-1950, 2006.

24. Smit JJ, Lindell DM, Boon L, Kool M, Lambrecht BN and Lukacs NW: The balance between plasmacytoid DC versus conventional DC determines pulmonary immunity to virus infections. PLoS One 3: e1720, 2008.

25. Vermaelen K and Pauwel R: Accurate and simple discrimination of mouse pulmonary dendritic cell and macrophage populations by flow cytometry: Methodology and new insights. Cytometry A 61: 170-177, 2004.

26. Venet F, Huang X, Chung CS, Chen Y and Ayala A: Plasmacytoid dendritic cells control lung inflammation and monocyte recruitment in indirect acute lung injury in mice. Am J Pathol 176 : 764-773, 2010

27. Masten BJ and Lipscomb MF: Comparison of lung dendritic cells and $\mathrm{B}$ cells in stimulating naive antigen-specific $\mathrm{T}$ cells. J Immunol 162: 1310-1317, 1999.

28. Liu H, Wu J, Yao JY, Wang H and Li ST: The role of oxidative stress in decreased acetylcholinesterase activity at the neuromuscular junction of the diaphragm during sepsis. Oxid Med Cell Longev 2017: 9718615, 2017.

29. Li L, Dong L, Wang Y, Zhang X and Yan J: Lats1/2-mediated alteration of hippo signaling pathway regulates the fate of bone marrow-derived mesenchymal stem cells. Biomed Res Int 2018 4387932, 2018

30. Li L, Dong L, Zhang J, Gao F, Hui J and Yan J: Mesenchymal stem cells with downregulated Hippo signaling attenuate lung injury in mice with lipopolysaccharide-induced acute respiratory distress syndrome. Int J Mol Med 43: 1241-1252, 2019.

31. Smith KM, Mrozek JD, Simonton SC, Bing DR, Meyers PA, Connett JE and Mammel MC: Prolonged partial liquid ventilation using conventional and high-frequency ventilatory techniques: Gas exchange and lung pathology in an animal model of respiratory distress syndrome. Crit Care Med 25: 1888-1897, 1997.

32. Hubbell JA, Thomas SN and Swartz MA: Materials engineering for immunomodulation. Nature 462: 449-460, 2009.

33. Lambrecht BN, Salomon B, Klatzmann D and Pauwels RA: Dendritic cells are required for the development of chronic eosinophilic airway inflammation in response to inhaled antigen in sensitized mice. J Immunol 160: 4090-4097, 1998.

34. Riccardi F, Della Porta MG, Rovati B, Casazza A, Radolovich D, De Amici M, Danova M and Langer M: Flow cytometric analysis of peripheral blood dendritic cells in patients with severe sepsis. Cytometry B Clin Cytom 80: 14-21, 2011.
35. Schlitzer A, Zhang W, Song M and Ma X: Recent advances in understanding dendritic cell development, classification, and phenotype. F1000Res 7, 2018.

36. Agrawal DK, Hopfenspirger MT, Chavez J and Talmadge JE: Flt3 ligand: A novel cytokine prevents allergic asthma in a mouse model. Int Immunopharmacol 1: 2081-2089, 2001.

37. Bohannon J, Fang G, Cui W, Sherwood E and Toliver-Kinsky T: Fms-like tyrosine kinase-3 ligand alters antigen-specific responses to infections after severe burn injury. Shock 32: 435-441, 2009.

38. Jankovic D, Liu Z and Gause WC: Th1- and Th2-cell commitment during infectious disease: Asymmetry in divergent pathways. Trends Immunol 22: 450-457, 2011.

39. Abe K, Nguyen KP, Fine SD, Mo JH, Shen C, Shenouda S, Corr M, Jung S, Lee J, Eckmann L and Raz E: Conventional dendritic cells regulate the outcome of colonic inflammation independently of T cells. Proc Natl Acad Sci USA 104: 17022-17027, 2007.

40. Beshara R, Sencio V, Soulard D, Barthélémy A, Fontaine J, Pinteau T, Deruyter L, Ismail MB, Paget C, Sirard JC, et al: Alteration of Flt3-Ligand-dependent de novo generation of conventional dendritic cells during influenza infection contributes to respiratory bacterial superinfection. PLoS Pathog 14: e1007360, 2018.

41. Madan B, Goh KC, Hart S, William AD, Jayaraman R, Ethirajulu K, Dymock BW and Wood JM: SB1578, a novel inhibitor of JAK2, FLT3, and c-Fms for the treatment of rheumatoid arthritis. J Immunol 189: 4123-4134, 2012

42. Kangelaris KN, Prakash A, Liu KD, Aouizerat B, Woodruff PG, Erle DJ, Rogers A, Seeley EJ, Chu J, Liu T, et al: Increased expression of neutrophil-related genes in patients with early sepsis-induced ARDS. Am J Physiol Lung Cell Mol Physiol 308: L1102-L1113, 2015.

43. Li H, Zhou X, Tan H, Hu Y, Zhang L, Liu S, Dai M, Li Y, Li Q, Mao Z, et al: Neutrophil extracellular traps contribute to the pathogenesis of acid-aspiration-induced ALI/ARDS. Oncotarget 9: 1772-1784, 2017.

44. Udayanga KG, Nakamura Y, Nakahashi-Oda C and Shibuya A: Immunoreceptor CD300a on mast cells and dendritic cells regulates neutrophil recruitment in a murine model of sepsis. Int Immunol 28: 611-615, 2016.

45. Sallusto F, Palermo B, Lenig D, Miettinen M, Matikainen S, Julkunen I, Forster R, Burgstahler R, Lipp M and Lanzavecchia A: Distinct patterns and kinetics of chemokine production regulate dendritic cell function. Eur J Immunol 29: 1617-1625, 1999.

46. Dransfield I and Rossi AG: Granulocyte apoptosis: Who would work with a 'real' inflammatory cell? Biochem Soc Trans 32: 447-451, 2004

47. Sharpe AH and Freeman GJ: The B7-CD28 superfamily. Nat Rev Immunol 2: 116-126, 2002.

48. Hathcock KS, Laszlo G, Pucillo C, Linsley P and Hodes RJ: Comparative analysis of B7-1 and B7-2 costimulatory ligands: Expression and function. J Exp Med 180: 631-640, 1994.

49. Xia W, Pinto CE and Kradin RL: The antigen-presenting activities of $\mathrm{Ia}^{+}$dendritic cells shift dynamically from lung to lymph node after an airway challenge with soluble antigen. J Exp Med 181: 1275-1283, 1995.

This work is licensed under a Creative Commons Attribution-NonCommercial-NoDerivatives 4.0 International (CC BY-NC-ND 4.0) License. 